\title{
Analysis of Site Response at U1A Hole at the Nevada Test Site from Weak Motion Recordings
}

\author{
L. Hutchings, L. Furrey
}

May 21, 2002

Lawrence

Livermore

National

Laboratory 


\section{DISCLAIMER}

This document was prepared as an account of work sponsored by an agency of the United States Government. Neither the United States Government nor the University of California nor any of their employees, makes any warranty, express or implied, or assumes any legal liability or responsibility for the accuracy, completeness, or usefulness of any information, apparatus, product, or process disclosed, or represents that its use would not infringe privately owned rights. Reference herein to any specific commercial product, process, or service by trade name, trademark, manufacturer, or otherwise, does not necessarily constitute or imply its endorsement, recommendation, or favoring by the United States Government or the University of California. The views and opinions of authors expressed herein do not necessarily state or reflect those of the United States Government or the University of California, and shall not be used for advertising or product endorsement purposes.

This work was performed under the auspices of the U. S. Department of Energy by the University of California, Lawrence Livermore National Laboratory under Contract No. W-7405-Eng-48.

This report has been reproduced directly from the best available copy.

Available electronically at http://www.doe.gov/bridge

Available for a processing fee to U.S. Department of Energy and its contractors in paper from

U.S. Department of Energy

Office of Scientific and Technical Information

P.O. Box 62

Oak Ridge, TN 37831-0062

Telephone: (865) 576-8401

Facsimile: (865) 576-5728

E-mail: reports@adonis.osti.gov

Available for the sale to the public from

U.S. Department of Commerce

National Technical Information Service

5285 Port Royal Road

Springfield, VA 22161

Telephone: (800) 553-6847

Facsimile: (703) 605-6900

E-mail: orders@ntis.fedworld.gov

Online ordering: $\underline{h t t p: / / w w w . n t i s . g o v / o r d e r i n g . h t m ~}$

OR

Lawrence Livermore National Laboratory

Technical Information Department's Digital Library

http://www.llnl.gov/tid/Library.html 


\title{
Analysis of Site Response at U1A hole at the Nevada Test site from Weak Motion Recordings
}

\author{
Lawrence Hutchings and Laura Furrey \\ Hazards Mitigation Center \\ Lawrence Livermore National Laboratory \\ Livermore, California 94551
}

\begin{abstract}
We utilize weak motion recordings to evaluate the site response at the U1A hole, Nevada Test site to determine the effect on potential ground motion at the drift of the U1A hole $962 \mathrm{ft}$ deep. We estimated the site response amplification of ground motion at the surface relative to the drift with the spectral ratio method. We utilized Fourier amplitude and absolute acceleration response spectra, and confined our study to frequencies of 0.5 to $25.0 \mathrm{~Hz}$ (.04 to $2.0 \mathrm{~s}$ periods). We identified 8 earthquakes in the area that were recorded at the bottom and top of the hole that were used for spectral ratios. We calculated the average and one standard deviation of ratios from all the events. Examining the data, we found that: 1) Fourier amplitude spectral ratios provided more detailed information on the site response than the absolute acceleration response that can be directly related to the effect of large earthquakes. 2) plots of the Fourier amplitude spectra for most of the recorded earthquakes show evidence for a spectral hole in the downhole recordings. This is due to downward reflected energy from the surface. This is not evident in absolute acceleration response records. 3) Fourier amplitude spectral ratios show a relative amplification at the surface of about a factor of eight for frequencies between about 9 to $15 \mathrm{~Hz}$ (.07 to .11 s periods) due to the spectral hole. 4) The free surface results in an amplification of about a factor of 2 for frequencies of about 13.0 to $25.0 \mathrm{~Hz}$ (.04 to $.08 \mathrm{~s}$ periods). 5) The geology results in an amplification of about a factor 2 of the surface relative to the bottom for frequencies 1.0 to $25.0 \mathrm{~Hz}(0.04$ to $1.0 \mathrm{~s}$ period). 6) A full site response function is provided as a function of frequency from the Fourier amplitude spectral ratios. This includes the effect of the spectral hole, free surface effect, and geologic amplification. It shows that strong ground motion would be diminished at the bottom of the U1A hole by a factor of .5 to 0.07 (as a function of frequency) for frequencies from 1.0 to $25.0 \mathrm{~Hz}$ (.04 to $.5 \mathrm{~s}$ periods). This is an estimation based upon linear ground motion response. More sophisticated soils modeling is necessary to determine whether non-linear ground motion may occur. More sophisticated ground motion modeling is necessary to determine under what conditions the spectral hole can diminish ground motions at the drift of the U1A hole $962 \mathrm{ft}$ deep.
\end{abstract}




\section{Introduction}

We have estimated the amplification of linear ground motion that occurs in wave propagation from the bottom (Drift) to the top (surface) of the U1A hole at the Nevada Test site. The hole is $962 \mathrm{ft}$ deep. In order to estimate the amplification we installed temporary recorders at the top and bottom of the hole to record nearby earthquakes. We identified eight events that were recorded at the top and bottom of the hole that were used for analysis. These events provided weak motion $(<0.01 \mathrm{~g}$ acceleration) records. Weak motion recordings offer the opportunity to utilize data that has propagation paths similar to that of large earthquake ground motion, allows sampling in-situ soil properties, and can be readily obtained in most seismically active regions. We used records of these small earthquakes to calculate spectral ratios in order to find amplification as a function of frequency. We utilized Fourier amplitude and absolute acceleration response spectra, and confined our study to frequencies of 0.5 to $25.0 \mathrm{~Hz}$ (.04 to $2.0 \mathrm{~s}$ periods). We calculated the average and one standard deviation of ratios from all the events.

It is important to emphasize that this is a preliminary analysis. First, we have not considered the phasing effects of wave propagation, only the amplitude effects. However, for this short distance differences in frequency components due to phasing should be minimal. This is supported by a previous study cited below. Second, this is strictly a linear analysis. The effects of very strong shaking cannot be determined in the manner reported here. One would have to synthesize a large incident wavefield at the Drift and propagate the waves up the soil column with an non-linear or equivalentlinear soils wave propagation code, such as SHAKE.

Techniques typically used to obtain site response estimates include Fourier amplitude spectral ratios of single events Borcherdt (1970) and averaged values from a number of events (Jarpe et al, 1989; Blakeslee and Malin, 1991), cross-spectral ratios (Steidl, 1993; Safak, 1997), coda spectral ratios (Aki, 1969; Malin, 1980), inverse methods (Glaser, 1995; Baise and Glaser, 2000). All these methods rely on proper reference sites for the site response calculation. In this study, site response is calculated from uphole/downhole pairs and spectral ratios will represent the mapping from downhole (reference site) to uphole ground motions for that site.

There are several issues that need to be addressed in order to have confidence in weak motion site response studies, including: 1 ) what is the best estimation procedure for determining earthquake site response, 2) what signal to noise ratio is necessary to obtain reliable site response estimates, 3) do weak motion estimates adequately sample full modal response of site geology, 4) what constitutes an adequate reference site, 5) what is the effect of recording at the bottom of a borehole, 6) do weak motion site response estimates adequately represent strong motion amplification (in the linear regime), 7) at what amplitudes does non-linear soil response occur. In this study number 3 and 6 were examined by developing equations for vertical wave propagation. They show that weak motion estimates adequately sample full modal response of site geology, and weak motion site response estimates adequately represent strong motion amplification (in the linear regime). Numbers $1,2,4$, and 6 are discussed in some detail here, and number 7 is outside the scope of this study and would require further study to address for the U1A hole.

Baise et al., (2001) studied several of these issues related to obtaining site response from up and downhole pairs. They identified 18 earthquakes that were recorded at the bottom and top of a 210 $\mathrm{ft}$ borehole at Yerba Island in the San Francisco Bay, California. Examining this data, they found 
that 1) the spectral ratio method gave very good results in identifying the site response of the medium and that it was not beneficial to attempt to include phasing effects in the site response analysis. 2) A signal-to-noise ratio of a factor of about 3 was sufficient to calculate site response. 3) plots of the spectra for most of the recorded earthquakes show evidence for a spectral hole in the downhole recordings between 8 and $11 \mathrm{~Hz}$ as compared to the uphole recordings. They attribute this to downhole recordings showing evidence of interference between the up and downgoing energy. A good discussion of spectral holes can be found in Safak (1997). Analysis of spectral holes for the U1A hole is provided below.

\section{Geology of the Study Area}

Figure 1 shows a cross-section of the U1A hole area. The surface is alluvium to about $1500 \mathrm{ft}$., and overlays Tertiary Tuffs. Figure 2 shows velocity logs of the hole. The velocity logs indicate that there are two different alluvium types over the depth of the hole. Plots of poisson's ratio, also shown in Figure 2 also indicate that there are two units of alluvium. The upper section to about a depth of $400 \mathrm{ft}$ has lower velocity and is presumable less compact than the upper alluvial section. The second section extents to below the $962 \mathrm{ft}$ deep hole.

\section{Instrumentation and Data}

Two Reftek recorders with S-13 seismometers were used to record events. Bob White (SNL, NTS) operated the recorders. Recorders were set to trigger on events and were recorded at 200 sps. We obtained two sets of data from Bob White: days 083 to 110 and days 110 to 147, 1998. We searched for earthquakes on the Univ. of Nevada catalog for these time periods, and couldn't find any events recorded at the U1A site from UNR catalogs. We then searched our data for local events that wouldn't be identified by the regional network. We looked at surface records for each event, low passed at $20 \mathrm{~Hz}$. If we found a significant event we searched for Surface and Drift pairs, sixteen pairs were identified. The origin of these earthquakes is not known since they were not recorded by a network, which is necessary to locate them.

A portable Refraction Technology 72A Data Acquisition Systems with 16 bit resolution was used to record the events. The reftek recorder has a roll-off at $250 \mathrm{~Hz}$ and imposes an anti-aliasing filter at $40 \%$ of the sampling rate. We sampled the reftek data at $200 \mathrm{sps}$, so it has a band limit of $80 \mathrm{~Hz}$. The S-13 seismometer is flat to velocity to at least $100 \mathrm{~Hz}$ and rolls off at the low frequency end; it is down $3 \mathrm{db}$ at $2 \mathrm{~Hz}$ and rolls off at $12 \mathrm{db}$ per octavo. We corrected for frequecny response so that it effectively has a flat frequency response to about $0.2 \mathrm{~Hz}$. The effective frequency range of the recording system then is about 0.2 to $80 \mathrm{~Hz}$. Cultural noise limited the analysis to about 0.5 to $25.0 \mathrm{~Hz}$.

\section{Theoretical Description}

Theoretically, site response can be analyzed as a medium through which transient waves pass (reflectivity analysis), through which modes of vibration are excited (modal analysis), as a site transfer function (system analysis), or as steady state wave propagation (SHAKE analysis). How do these methods of analysis relate to each other and what do they contribute to understanding of site response. Here, we will formulate a simple model for site response calculations and compare analytical techniques. Consider a vertically propagating shear-wave in an visco-elastic rock half-space incident upon a layered ( $\mathrm{N}$ layers), damped, soil column. Assuming that half space behaves as a 
Kelvin-Voigt solid, the wave equation within the half-space and soil column is in the form (Schnabel et al., 1972; Kramer, 1997):

$$
\rho \frac{\partial^{2} u}{\partial t^{2}}=G \frac{\partial^{\dot{2}} u}{\partial z^{2}}+\eta \frac{\partial^{3} u}{\partial z^{2} \partial t}
$$

where $u(z, t)$ only has particle motion in the horizontal direction so we are examining an SH-wave problem; $\rho(z)$ is material density, $G(z)$ is shear modulus, and $\eta(z)$ is viscosity. A solution to the homogeneous wave equation is:

$$
u(z, t)=A_{m} e^{i\left(\omega t+k_{m}^{*} z+\Phi_{m}^{+}(\omega)\right)}+B_{m} e^{i\left(\omega t-k_{m}^{*} z+\Phi_{m}^{-}(\omega)\right)}
$$

where $A_{m}$ and $B_{m}$ are real constants and are amplitudes of the waves at layer $m$. The first term after the equals sign is up going energy propagating in the $-\mathrm{z}$ direction and the second term is down going energy propagating in the $+\mathrm{z}$ direction, and $k^{*}$ is the complex wave number

$$
k_{m}^{*}=\omega \sqrt{\frac{z}{G+i \omega \eta}}
$$

and $\Phi_{m}^{ \pm}(\omega)$ is the phase for up, + , and down, -, going energy and is determined below. When the complex wave number is put into the solution for the wave equation, the imaginary part describes the oscillatory motion and the real part describes the damping. This solution is for a particular frequency $\omega$.

Consider a solution in the half-space, just below the interface with the soil column where we require the initial conditions for up-going energy to be that $A_{N+1}=1$ and have zero phase shift for all frequencies in the half space. Also, consider a solution for the down-going energy that is a sum of solutions, each one of which solves the wave equation and is the result of the up-going delta function having traveled through a number of layers and returning to the half space with amplitude determined by the reflection-transmission coefficients (Aki and Richards, 1980, ch. 4);

$$
B_{N+1} \Rightarrow \sum_{1}^{K} B_{K}^{L}
$$

where $\mathrm{k}$ is the number of arrivals in the layer; where, each arrival has passed through $L$ layers. As- 
sociated with each arrival is a phase delay from the arrival having travel through $L$ layers:

$$
\Phi_{K}^{-}(\omega)=\omega \sum_{l=1}^{L} \frac{z_{l}}{c_{l}}
$$

also, there is attenuation from the complex wavenumber from having traveled through $L$ layers:

$$
\left(k^{*} z\right)_{K}=\omega \sqrt{\sum_{l=1}^{L} \frac{z_{l}^{3}}{G_{l}+i \omega \eta_{l}}}
$$

Integrating over all frequencies to get the full signal and starting with $\mathrm{z}=0$ :

$$
u\left(z_{N+1}, t\right)=\int_{0}^{\infty}\left(e^{i \omega t}+\sum_{1}^{K} B_{K} e^{i\left(\omega t-\left(k^{*} z\right)_{K}+\Phi_{K}^{-}(\omega)\right)}\right) d \omega
$$

where, we recognize the first term after the first equals sign as the fourier transform of the delta function. The delta function is up-going energy from the half-space and the second term is down going energy from the soil column. $B_{K}$ are coefficients of the reflected arrivals from the layers in the soil column. Therefore, we have the full solution at layer $\mathrm{N}+1$ for a vertically incident delta function propagating from the half space. To determine the Coefficients $B_{K}$, follow Schnabel and Seed (1972), and introduce a local coordinate system, $Z$ for each layer. At each acoustic interface a reflection will result in another delta function with time delay after the initial incident delta function, in the frequency domain the phase for the up + or down - going wave, $L$ is the number layers that wave $m$ has passed through, $z_{l}$ is their thickness and $c_{l}$ is their velocity. So, the recursive formulas for amplitude in any layer with respect to the incident amplitudes can easily be calculated: so that $A_{K}\left(A_{i n c}\right)$ and $B_{K}\left(A_{i n c}\right)$.

The integrand of the second integral in equation (7) is recognized as a series of delta functions with phase delays and damping. Now, the site transfer function for the recording at the bottom of a borehole and in rock, from equation (2) and (7), in the frequency domain:

$$
R\left(z_{0}, z_{N+1}, \omega\right)=\frac{2 \int_{0}^{\omega}\left(\sum_{1}^{K} A_{K} \delta\left(t+\left(k^{*} z\right)_{K}-\tau_{K}\right)\right)_{z_{0}} e^{-i \omega} d \omega}{\int_{0}^{\omega}\left(\delta(t)+\sum_{1}^{K} B_{K} \delta\left(t+\left(k^{*} z\right)_{K}-\tau_{K}\right)\right)_{z_{N+1}} e^{-i \omega} d \omega}
$$

where $K$ is a local variable for each layer and evaluated at $\mathrm{z}=0$ (surface) and $\mathrm{z}=\mathrm{N}+1$, and we have 
taken the Fourier transform of the time series. The factor of two in the numerator is due to the free surface effect of down-going energy equalling minus the up-going energy. We can see that the time series is a summation of delta functions and time delays by the propagation through the layers, whose amplitude are controlled by the transmission and reflection coefficients. Attenuation results in a non-causal spreading of the delta functions and we refer to the anzi solution to maintain causality, but it is not applied in this demonstration. The site transfer function could be estimated inversely using surface to borehole ground motion data and cross-spectral ratios or system identification of ARMA models. If a rock outcrop site were used as a reference site, then the denominator would be just the delta function multiplied by two. Equation (6) also corresponds to the estimated site transfer function for some forward models. The SHAKE estimated transfer function does not include the phase information.

If there were no layers and only the free surface is apparent from equation 7 that the spectra at the bottom of the borehole would be:

$$
u(z, t)=\int_{0}^{\infty}\left(e^{i \omega t}+B_{K} e^{i\left(\omega t-\left(k^{*} z\right)\right)} d \omega z 1+B \cos \left(k^{*} z\right)\right.
$$

for the real part, which will result in a scalloped spectra at pi/2 multiples of $k^{*} z$. Thus, the location of the borehole results in holes in the downhole spectra.

\section{Signal to Noise Ratios}

For weak motion recordings, the noise in the signal is often the limiting factor for site response studies. The SNR for each earthquake in this study was calculated by estimating the spectral content of the first 20 to 30 seconds of the record (depending on the length of noise recorded prior to the earthquake signal) and a similar length of the earthquake signal. The two components of horizontal motion were combined into a complex signal as described by Steidl et al (1996). Fourier amplitude spectra of velocity records are used for the analysis. The Fourier signal amplitude spectrum was then divided by the Fourier noise spectrum for that earthquake. The SNR was calculated for the uphole and downhole recorded motions. A limiting SNR of 3:1 was chosen to determine the usable frequency band of each signal. Frequencies where the SNR was below 3 are believed to be contaminated by the noise.

\section{Spectral Holes}

Plots of the Fourier amplitude spectra for most of the recorded earthquakes show evidence for a spectral hole in the downhole recordings between 9 and $15 \mathrm{~Hz}$ as compared to the uphole recordings. The spectral hole is identified as such because spectra of the downhole recordings show a loss of energy over the frequency band, or rather an indent in an otherwise smooth spectra. The uphole spectra is smooth with a constant slope throughout this frequency range. Examining Figures $10-18$ it is apparent that there is a notch in the downhole spectra near $10 \mathrm{~Hz}$. This results in an apparent amplification in this frequency range when the spectral ratio is taken with the up-hole records. This effect is not apparent when the spectral ratio of the absolute acceleration response is 
take (Figures 2 - 10) because the acceleration response spectra smooth spectra over several frequencies. The spectral hole varies in width and depth over the earthquakes in this study, but is consistently observed for all earthquakes.

Spectral holes in downhole records are common and are due to destructive interference of up- and down-going energy. Downhole records are a combination of up-going energy and down-going energy delayed by the two-way travel time to the surface and back. An incident delta function recorded at the bottom of a borehole, for example, will result in two delta functions delayed by the twoway travel time. A simple Fourier transform to get the amplitude spectra will show that this results in a scalloping of the spectra at multiplies of the two-way travel time. This is show above when discussing equation 7. For a two-way travel time of the surface reflection (1924 ft total), and an assumed shear wave velocity of about $1.0 \mathrm{~km} / \mathrm{s}$, a spectral hole would be expected around $10 \mathrm{~Hz}$ for this study, and this is in the range of what is observed. Spectral holes are real in nature and result in a depletion of energy, so that at the bottom of the borehole one expects lower amplitude at these frequencies.

\section{Free surface Effect}

One might expect the free surface to cause the well know amplification of a factor of two for vertically propagating shear waves. However, this would only be true for frequencies that are short enough that the waves have a couple of cycles between the free surface and the downhole site. Or, wavelengths are shorter than the distance between the up and down hole site. Assuming four wavelengths, the free surface should result in an amplification of about a factor of 2 for frequencies greater than about $13.0 \mathrm{~Hz}$ (.04 to $.08 \mathrm{~s}$ periods). Steidl (1995) suggest that this frequency is observed by examining the frequency when the spectral ratio increases by a factor of two. Examining the spectral ratios in Figures 11 to 19, it appears that the overall amplitude of the spectral ratios increases by about two for frequencies greater than around 15 relative to those below about $10 \mathrm{~Hz}$. The spectra hole interferes with observations between 9 and $15 \mathrm{~Hz}$. This is consistent with the calculation of the frequency where the effect should be observed.

\section{Site Response}

Spectral ratios from the bottom to the top of the borehole were obtained from the average of the horizontal component spectra. The basic assumption of the spectral ratio methods is that travel paths and source effects of the aftershocks will be the same for both sites so that the ratio will show the amplification between the bottom and top of the borehole. In the following $\left|X_{1}\right| e^{\phi_{X 1}},\left|X_{2}\right| e^{\phi_{X 2}}$, $\left|Y_{1}\right| e^{\phi_{Y 1}}$, and $\left|Y_{2}\right| e^{\phi_{Y 2}}$ are the Fourier transforms of the two horizontal components for the up- and down-hole records, respectively. All following relationships are a function of frequency. Details such as instrument response, propagation path effects, and effect of noise are ignored in the following relationships, but are handled as discussed in many previous studies, such as Bonilla et al (1997) and Safak (1997), and Steidl (1993).

The average of horizontal component's spectral ratios $(A H S R)$ is calculated from just the amplitude 
spectra by:

$$
A H S R=\frac{\left(\left|X_{1}\right| \div\left|Y_{1}\right|\right)+\left(\left|X_{2}\right| \div\left|Y_{2}\right|\right)}{2}
$$

In an effort to find a simple transfer function with one amplitude spectrum that is independent of geometry and one phase spectrum that is a function of the horizontal component's phase spectrums, we define each vector amplitude phase spectrum as the average of those from the two components:

$$
\phi_{X}=\frac{\phi_{X 1}+\phi_{X 2}}{2} \quad \text { and } \quad \phi_{Y}=\frac{\phi_{Y 1}+\phi_{Y 2}}{2}
$$

and the transfer function phase spectrum as:

$$
\phi_{X Y}=\phi_{X}-\phi_{Y}
$$

Two horizontals, if available were used for analysis. Seismograms were differentiated to acceleration. Units are $\mathrm{cm} / \mathrm{sec}^{*} \mathrm{sec}$. It is important to know that accelerations recorded were very small, so that all motions discussed are in the linear response range for soil. Figures 3 - 11 show the accelerograms, absolute acceleration response spectra, and the ratio of the spectra (labeled Site Response). The site response curve is used to identify the amplification as a function of period for wave propagation from the bottom to the top of the U1A hole. Figures $12-18$ show the same accelerograms, their Fourier amplitude spectra, and the ratio of the Fourier amplitude spectra. The figures show the event identification number and surface or drift, along with component identification. The curves have been smoothed. Figure 19 shows the mean and plus and minus one standard deviation values for the 8 spectral ratios of absolute acceleration response and fourier amplitude response, respectively. These curves constitute our estimate of the linear ground motion for wave propagation from the bottom to the top of the U1A hole.

\section{Conclusions}

We utilize weak motion recordings to evaluate the site response at the U1A hole, Nevada Test site to determine the effect on potential ground motion at the drift of the U1A hole $962 \mathrm{ft}$ deep. We estimated the site response amplification of ground motion at the surface relative to the drift with the spectral ratio method. We utilized Fourier amplitude and absolute acceleration response spectra, and confined our study to frequencies of 0.5 to $25.0 \mathrm{~Hz}$ (.04 to $2.0 \mathrm{~s}$ periods). We identified 8 earthquakes in the area that were recorded at the bottom and top of the hole that were used for spectral ratios. We calculated the average and one standard deviation of ratios from all the events. Examining the data, we found that: 1) Fourier amplitude spectral ratios provided more detailed 
information on the site response than the absolute acceleration response that can be directly related to the effect of large earthquakes. 2) plots of the Fourier amplitude spectra for most of the recorded earthquakes show evidence for a spectral hole in the downhole recordings. This is due to downward reflected energy from the surface. This is not evident in absolute acceleration response records. 3) Fourier amplitude spectral ratios show a relative amplification at the surface of about a factor of eight for frequencies between about 9 to $15 \mathrm{~Hz}$ (.07 to .11 s periods) due to the spectral hole. 4) The free surface results in an amplification of about a factor of 2 for frequencies of about 13.0 to $25.0 \mathrm{~Hz}$ (.04 to $.08 \mathrm{~s}$ periods). 5) The geology results in an amplification of about a factor 2 of the surface relative to the bottom for frequencies 1.0 to $25.0 \mathrm{~Hz}(0.04$ to $1.0 \mathrm{~s}$ period). 6) A full site response function is provided as a function of frequency from the Fourier amplitude spectral ratios. This includes the effect of the spectral hole, free surface effect, and geologic amplification. It shows that strong ground motion would be diminished at the bottom of the U1A hole by a factor of .5 to 0.07 (as a function of frequency) for frequencies from 1.0 to $25.0 \mathrm{~Hz}$ (.04 to $.5 \mathrm{~s}$ periods). This is an estimation based upon linear ground motion response. More sophisticated soils modeling is necessary to determine whether non-linear ground motion may occur. More sophisticated ground motion modeling is necessary to determine under what conditions the spectral hole can diminish ground motions when earthquake occur on nearby faults and the geology is not flat layered.

\section{Recommendations}

The purpose of this study was to determine the effect on potential ground motion at the drift of the U1A hole $962 \mathrm{ft}$ deep. In order to evaluate this further it is recommend that full waveform analysis be performed., First, ground motion from potential larger earthquakes can be synthesized. Utilizing the recordings of nearby small earthquakes in the ground motion synthesis can provide constraints on wave propagation and inherently include the site response effects discussed in the this report. However this analysis is strictly linear. A non-linear convolution of the input ground motion with the soil column at the U1 A hole is necessary to determine whether non-linear effects are important to this site. The equivalent-linear program SHAKE could be used or more sophisticated programs that actually model the full physics of the soil response could be used.

\section{References}

Aki, K. (1969) Analysis of the seismic coda of local earthquakes as scattered waves. J. Geophys. Res. 74, 615-631.

Aki, K. and P. G. Richards (1980). Quantitative seismology, Theory and Methods, Volumes I and II, W. H. Freeman and Company, San Francisco, CA.

Aster, R.C. and P.M.Shearer (1991) High-frequency borehole seismograms recorded in the San Jacinto fault zone, southern California, 2, Attenuation and site effects. Bul. Seis. Soc. Am. 81, 10811100.

Baise, Laurie, Lawrence Hutchings, and Steven Glaser (2001) Analysis of Site Response at Yerba Buena Island, San Francisco Bay, California from Weak Motion Recordings. in press, Special Issue on Site Response, Bollettino di Geofisica, Trieste, Italy.

Baise, L.G. and S.D. Glaser (2000). Consistency of Ground-Motion Estimates made using System Identification. Bul. Seis. Soc. Am. 90, 993-1009.

Blakeslee, S. and P. Milan (1991) High-frequency site effects at two Parkfield downhole and sur- 
face stations. Bul. Seis. Soc. Am. 81, 332-345.

Bonilla, Luis Fabian, Jamison H. Steidl, Grant T. Lindley, Alexei G. Tumarkin, and Ralph J. Archuleta (1997) Site amplification in the San Fernando valley, CA: variability of the site effect estimation using the S-wave coda, and H/V methods. Bul. Seis. Soc. Am. 87, 710-730.

Borcherdt, R.D. (1970) Effects of local geology on ground motion near San Francisco Bay. Bul. Seis. Soc. Am. 60, 29-61.

Borchert, D. Roger, James F. Gibbs, and Kenneth R. Lajoie (1975) Maps Showing Maximum Earthquake Intensity, Predicted in the southern San Francisco Bay Region, California, for Large Earthquake on the San Andreas and Hayward Faults. Sheet 3: Generalized Geology Map.

Brillinger, D.R. (1975). Time Series: Data Analysis and Theory. Holt, Rinehart and Wilson, Inc. New York.

Safak, Erdal (1997) Models and Methods to Characterize Site Amplification from a Pair of Records. Earthquake Spectra, V. 13, No. 1, pp. 97-129.

Steidl, Jamison H., Alexei G. Tumarkin, and Ralph J. Archuleta (1996) What is a reference site? Bul. Seis. Soc. Am. 86, pp. 1733-1748.

\section{Acknowledgments}

This work was funded by Caltrans, contract no. 59A0238, by LLNL, CLC project, and by the LLNL Engineering Doctorate under the direction of Tony Davito. We have benefited from discussions with Paul Kasameyer, Laurie Baise, Alexei Tumarkin, Jamie Steidl, and Bill Foxall. This work was performed under the auspices of the U.S. Department of Energy by the University of California, Lawrence Livermore National Laboratory under contract No. W-7405-Eng-48.

\section{Figures}

Figure 1: Geologic cross-section of the U1A hole area.

Figure 2: Velocity logs of the U1A hole (left), and Poisson's ratio obtained from logs (right).

Figures 3 - 10: Time series of recorded ground motion (left) at the surface and bottom (Drift) of the U1A hole; absolute acceleration response of the surface and borehole recordings (top right), averaged for the two horizontal recordings shown; and, the ratio of the spectra to get site response (bottom right).

Figures 11-18: Time series of recorded ground motion (left) at the surface and bottom (Drift) of the U1A hole; Fourier amplitude spectra of the surface and borehole recordings (top right), averaged for the two horizontal recordings shown; and, the ratio of the spectra to get site response (bottom right).

Figure 19: Average and plus and minus standard deviation of the site response as obtained from absolute acceleration response calculations (left); and, average and plus and minus standard deviation of the site response as obtained from Fourier amplitude spectra (right). 


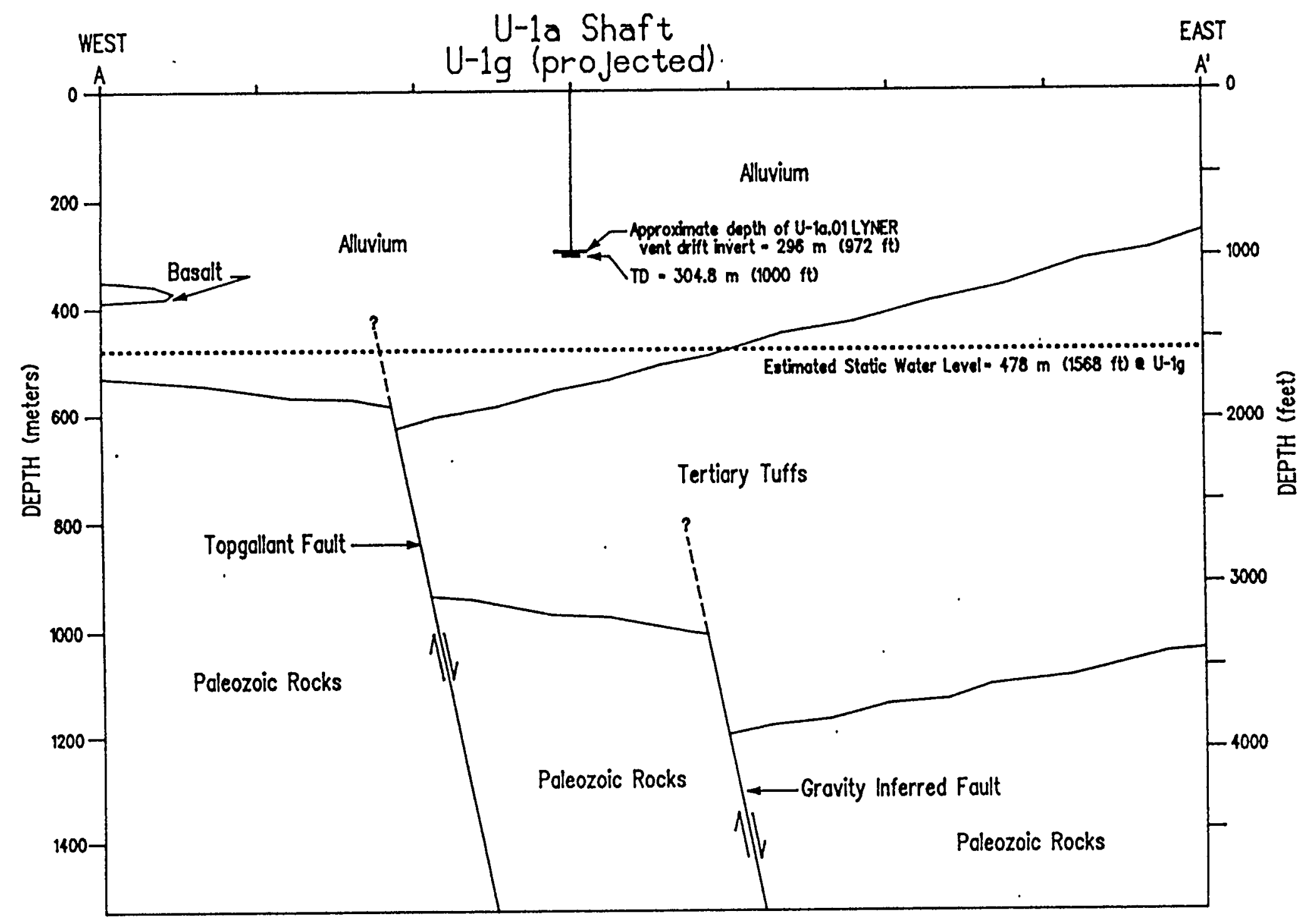

Note: Cross-section line is due west-east through $U$-la.

Bechitel Nevade Geology/Hydrology 2/96

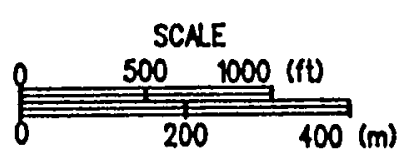

Figure 1. WEST-EAST GEOLOGIC CROSS-SECTION (A-A') THROUGH U-1g/LYNER COMPLEX. 


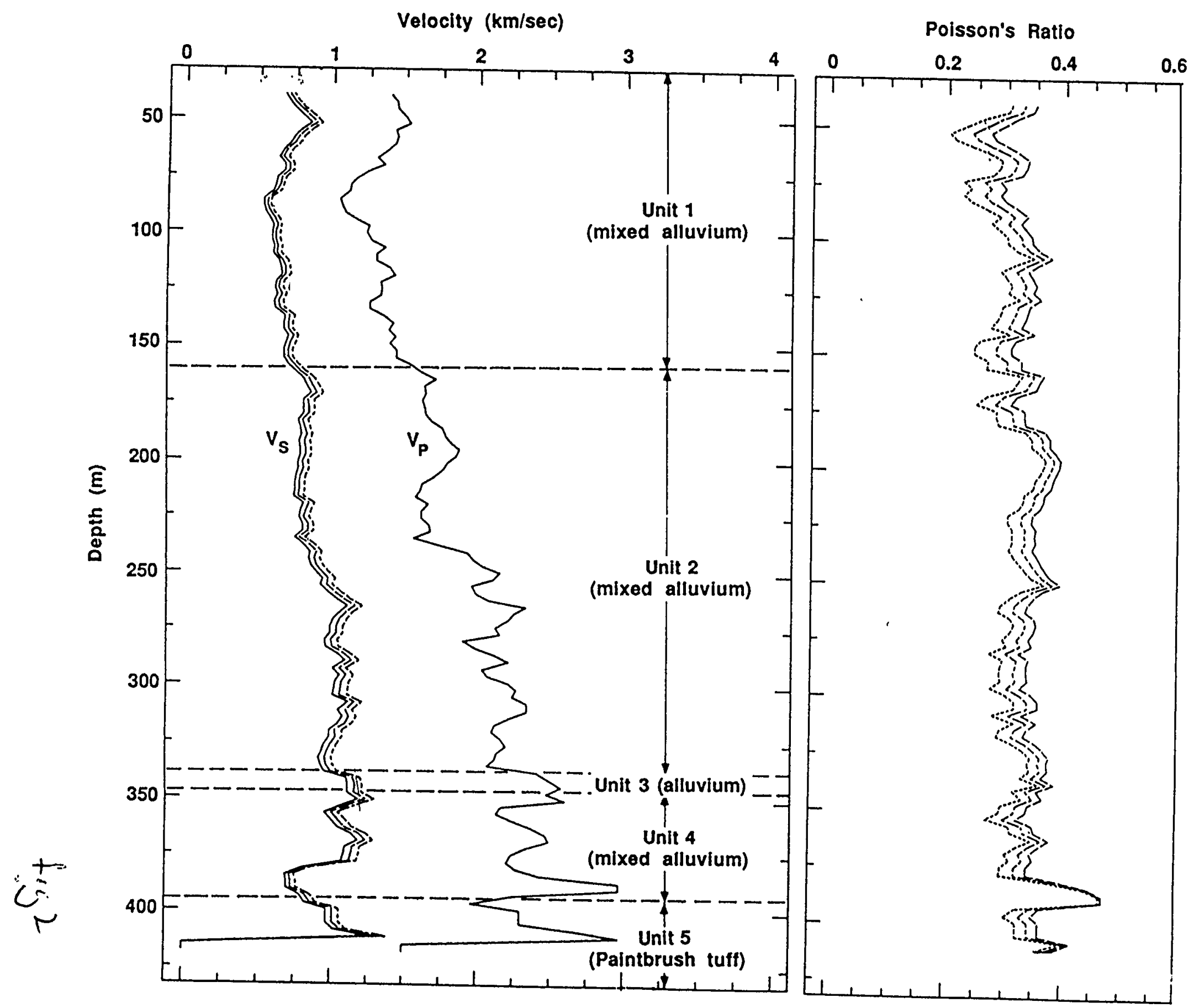


Event 04272122

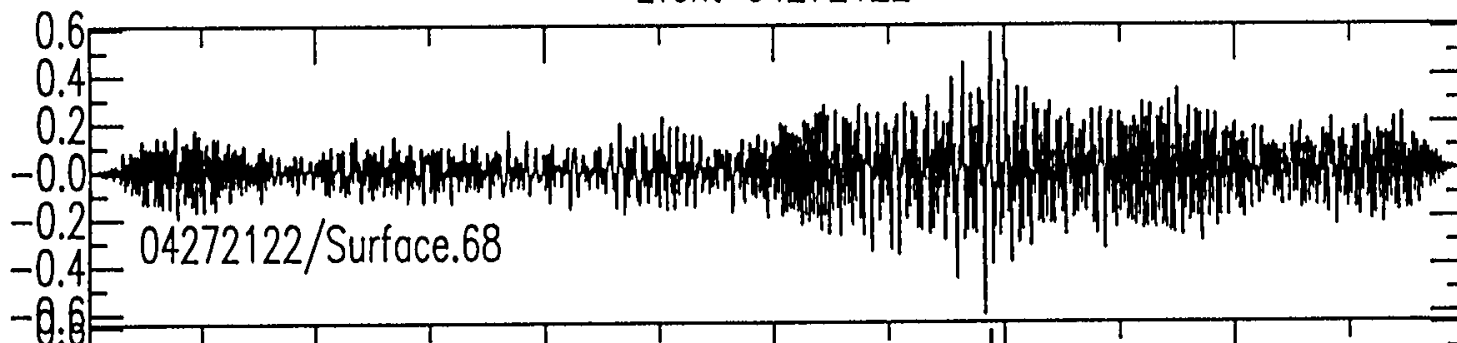

$0.4 E$

$80.2=$

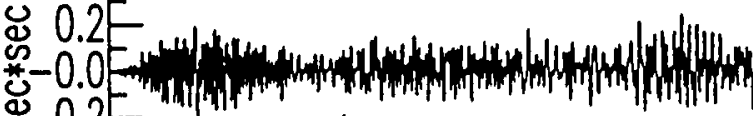

$\stackrel{\infty}{\infty} 0.2 E$ E $04272122 /$ Surface.68

ह-0.4

.0.0.04

잉 0.00

$80.02=04272122 /$ Drift.68

$-0.06=$

$0.04 E$

$0.02=$

-0.02
-0.04 04272122/Drift.68

$-0.06 E$

$\frac{\hbar}{c^{\prime}}$
Absolute Acceleration Response

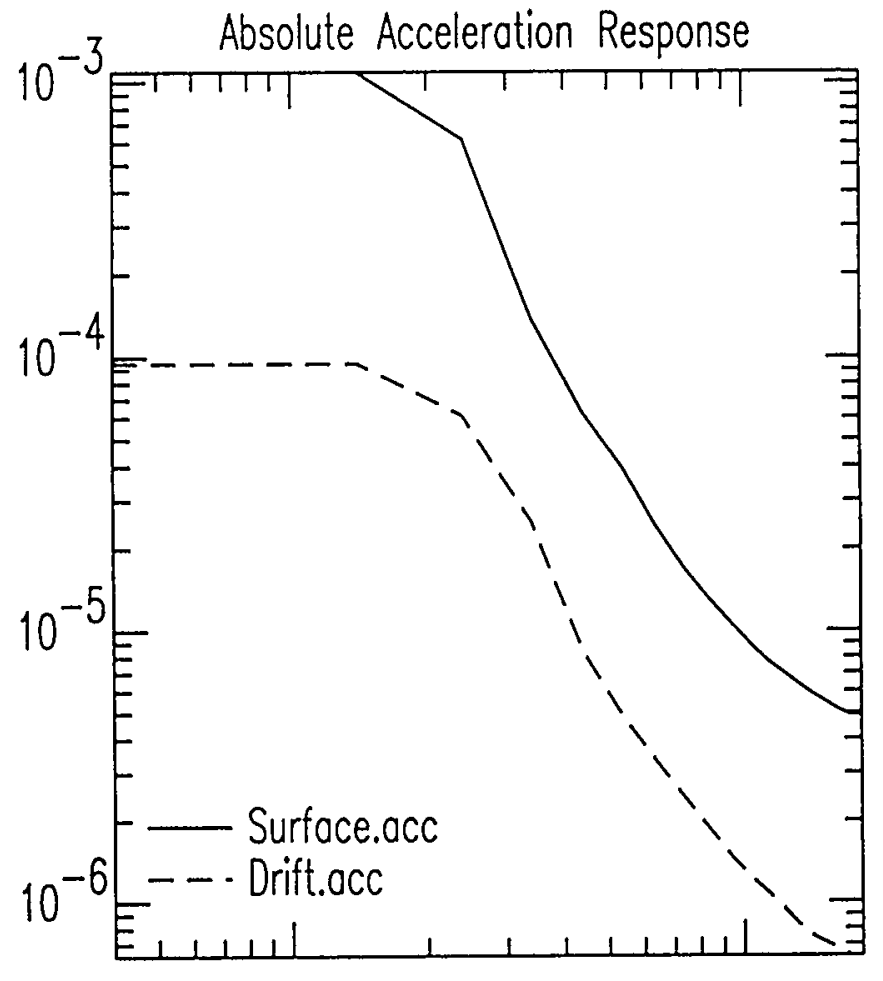

Site Response

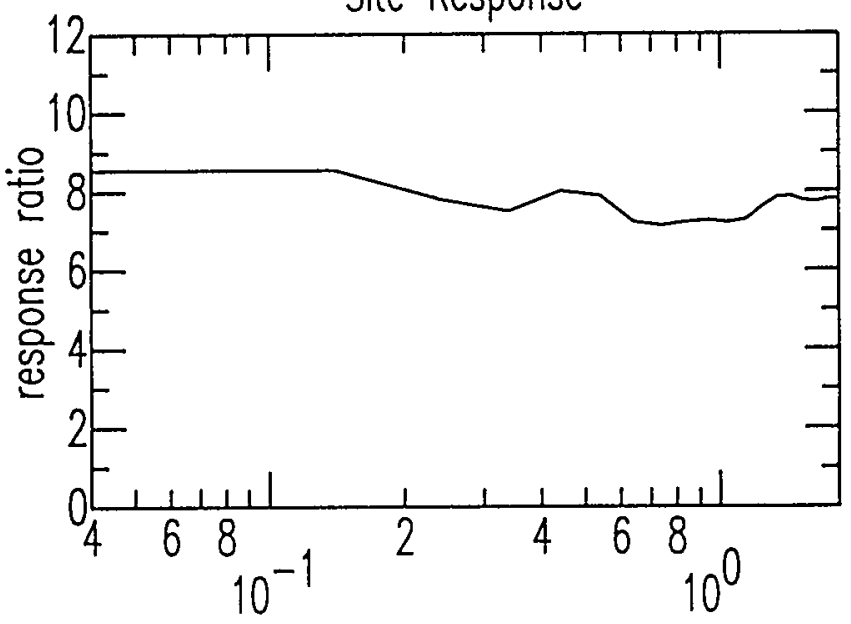

Period 

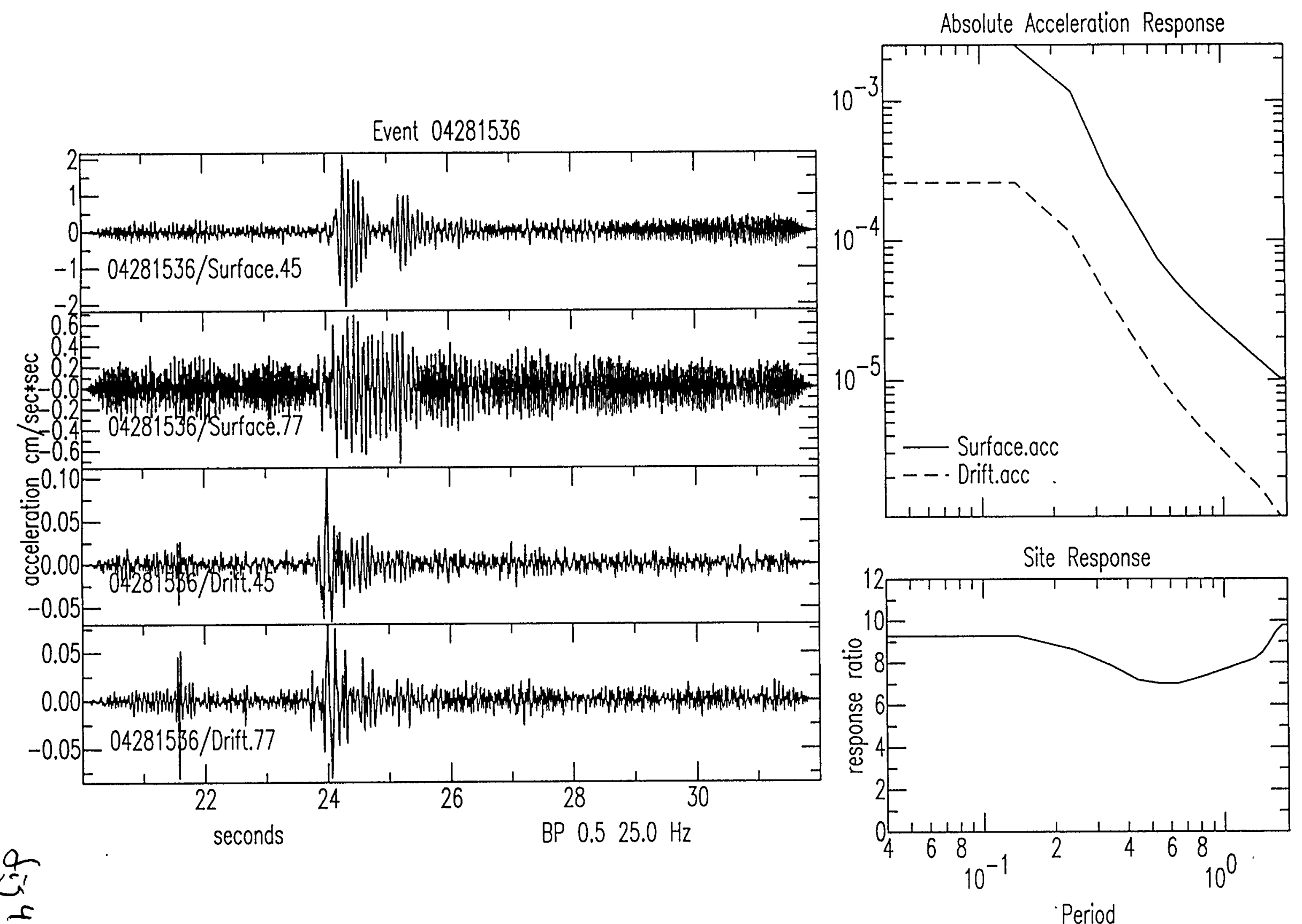

- Period 
Absolute Acceleration Response

Event 05011833
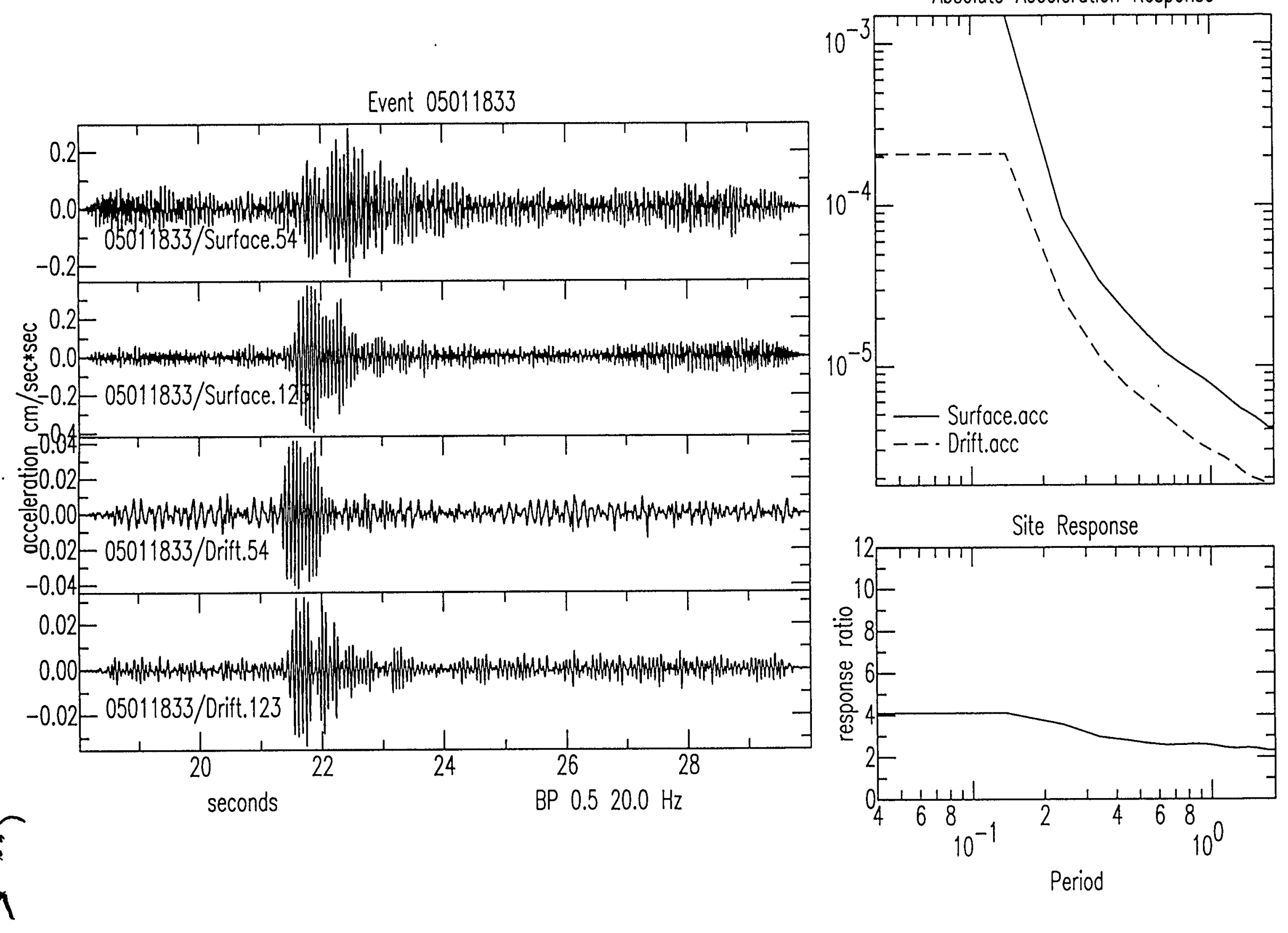

Period 
Absolute Acceleration Response

Event 05072040
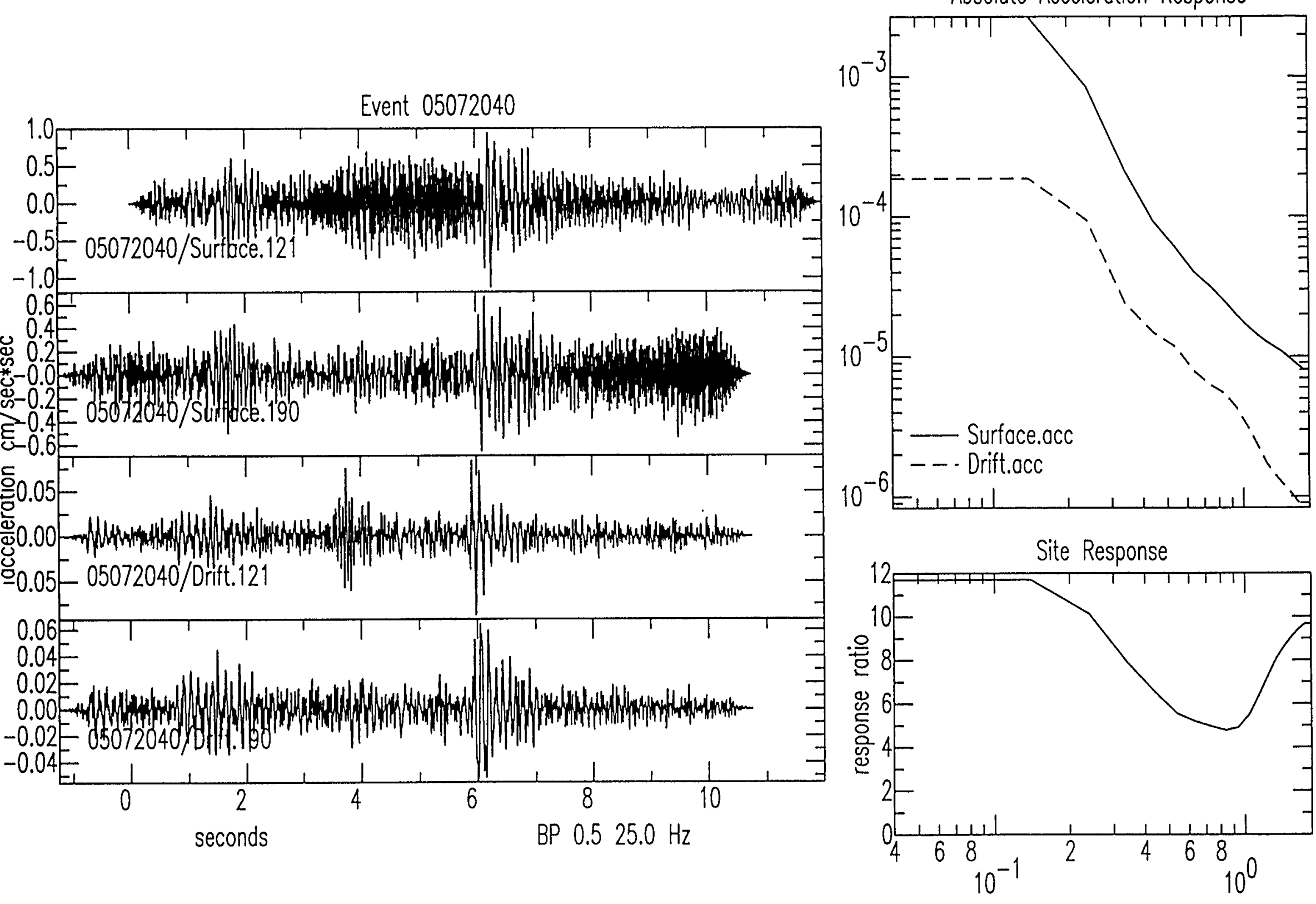

Period 
Event 05072108
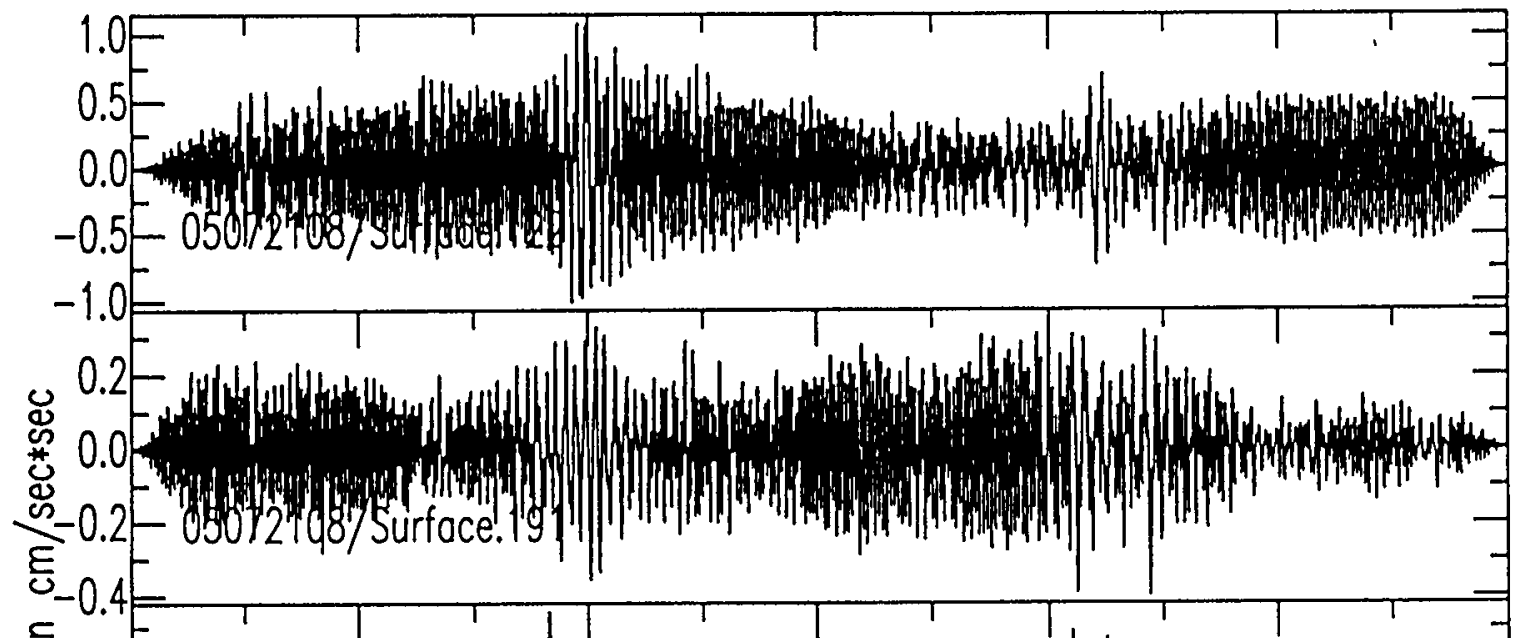

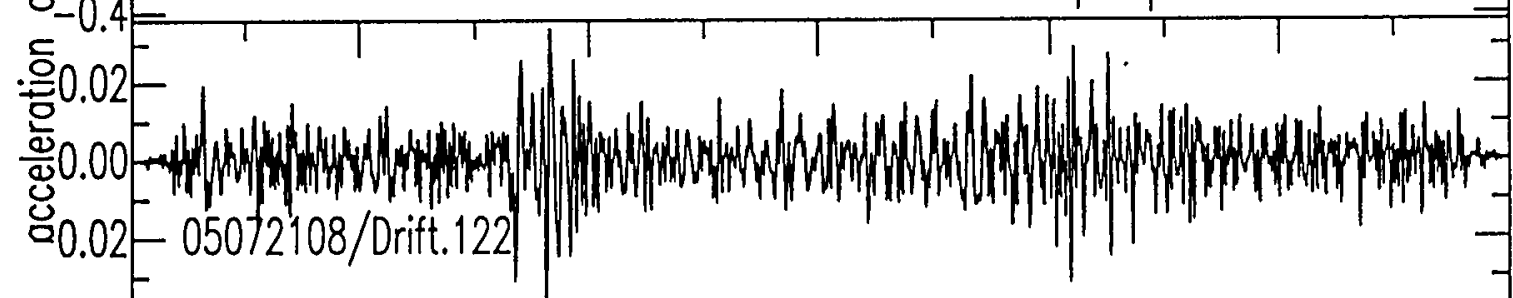

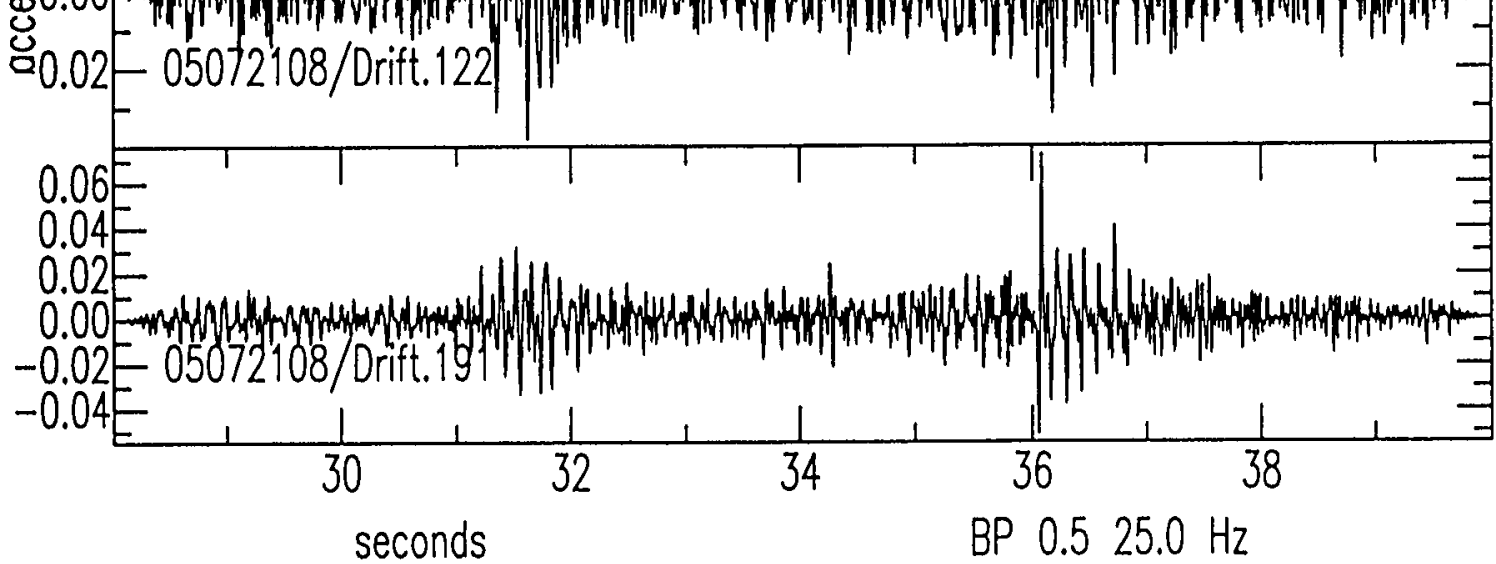

in
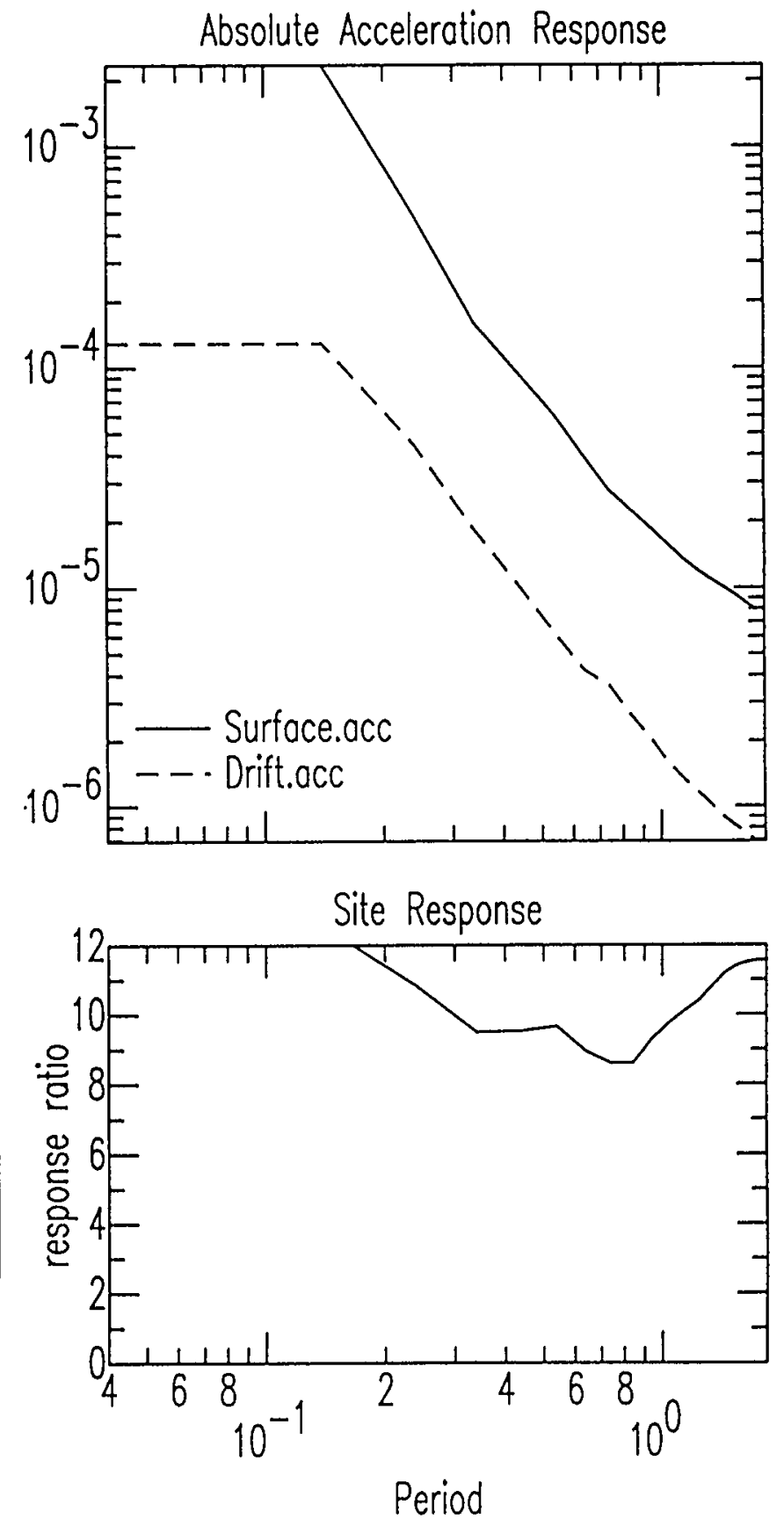

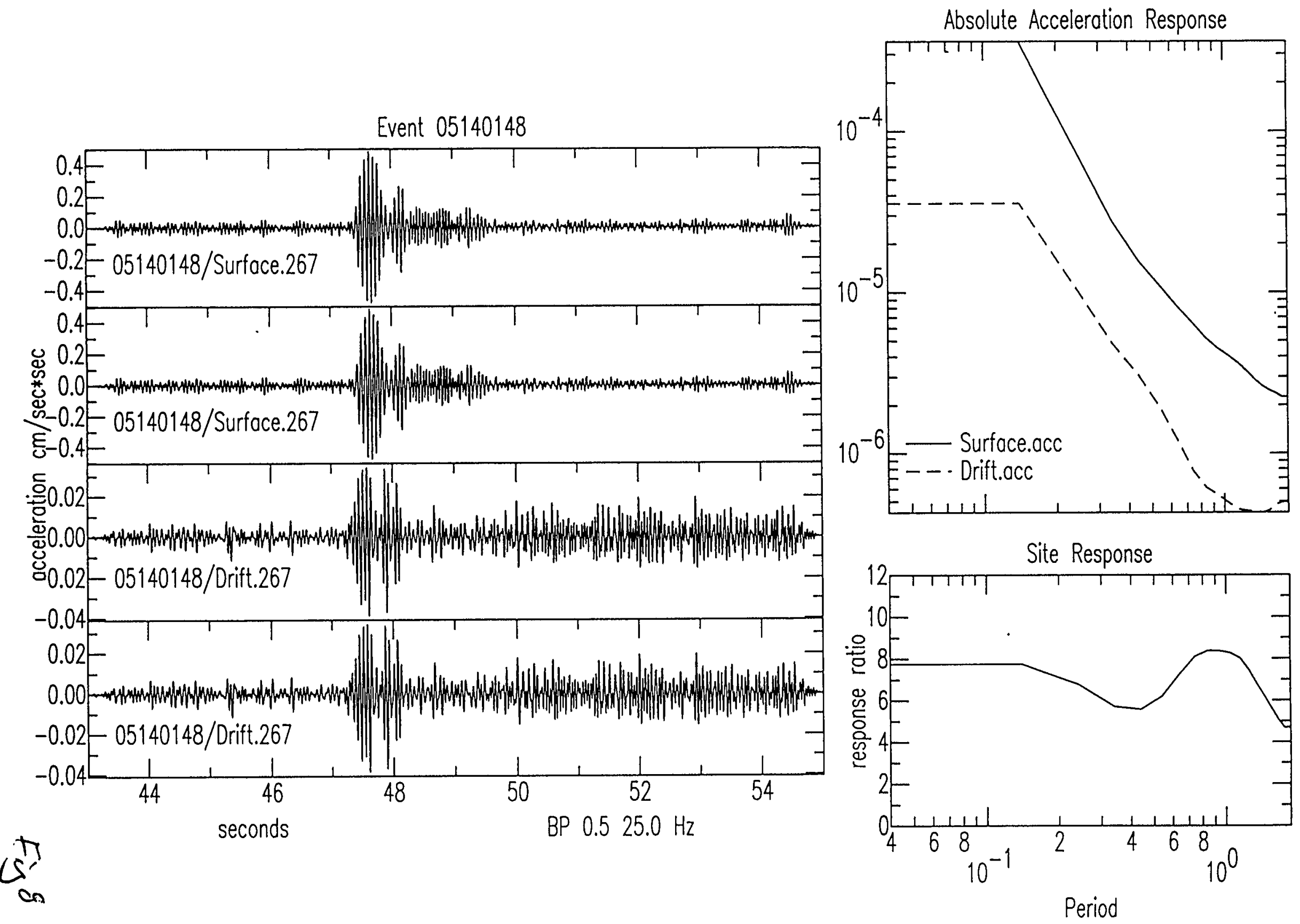
Event 05182043
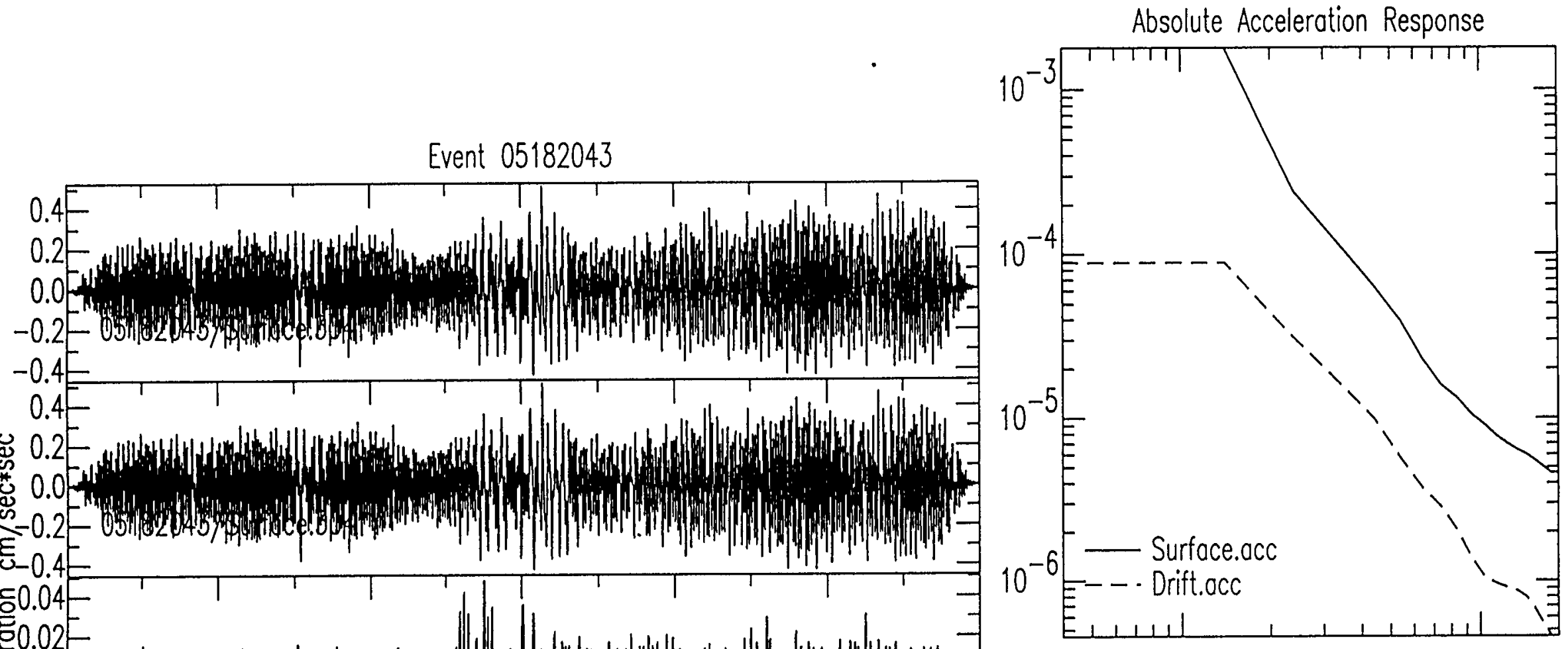

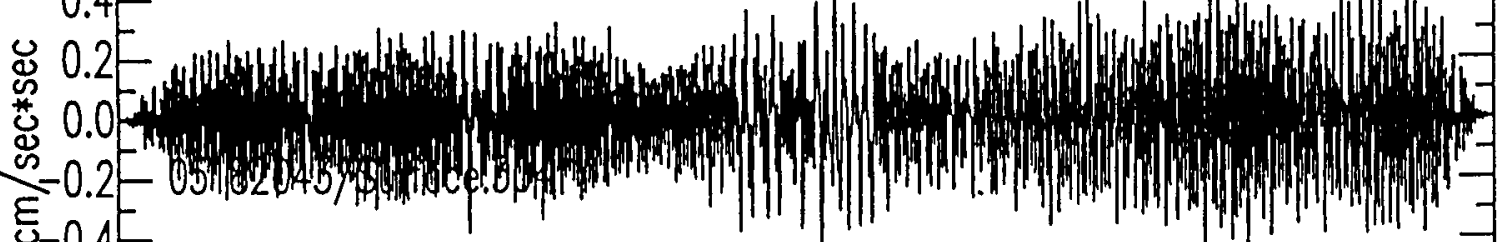
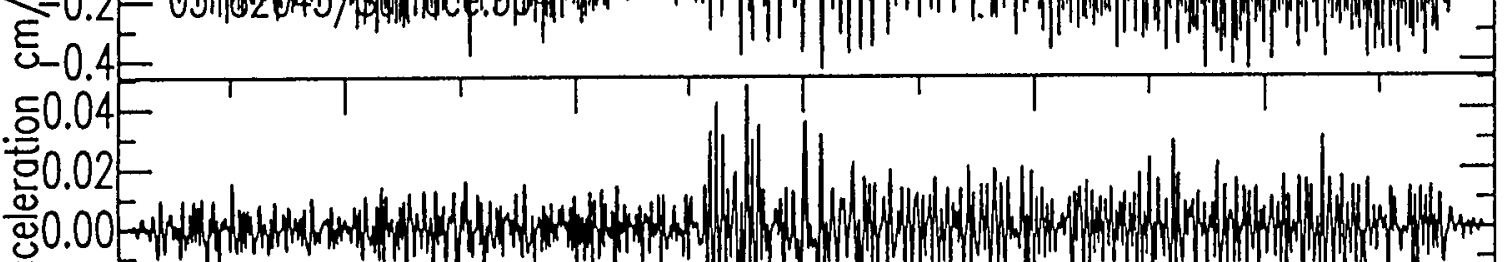
○0.02E-05182043/Dritt.304
$-0.04-$

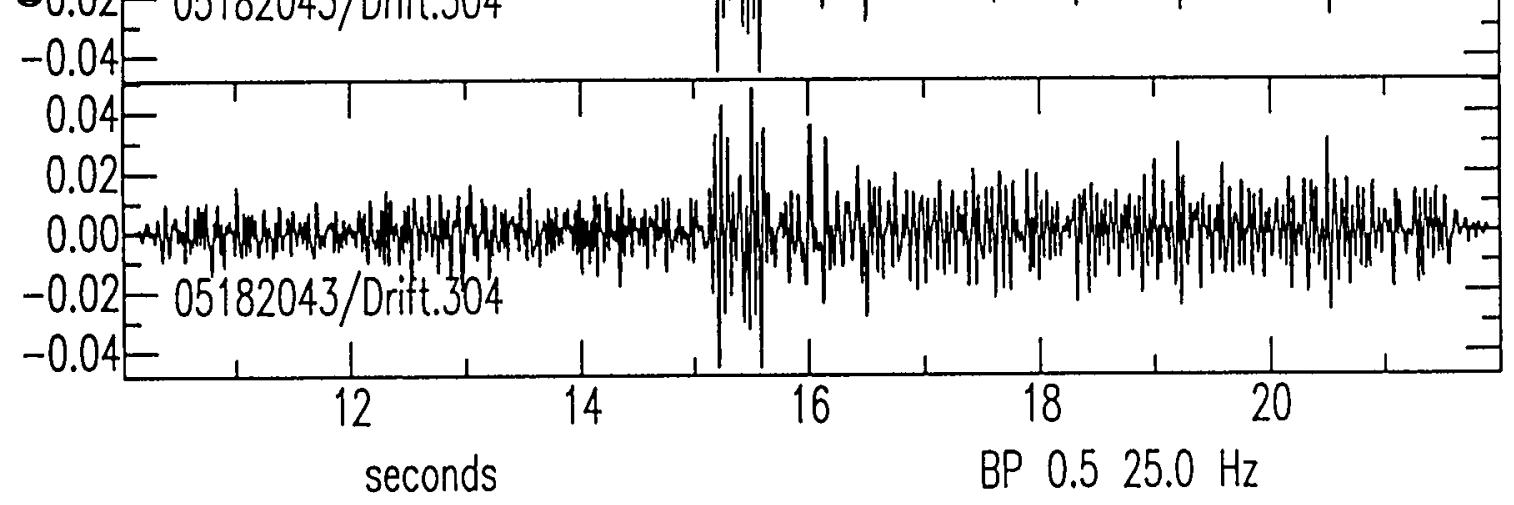

$\sin _{\rightarrow}^{\pi}$

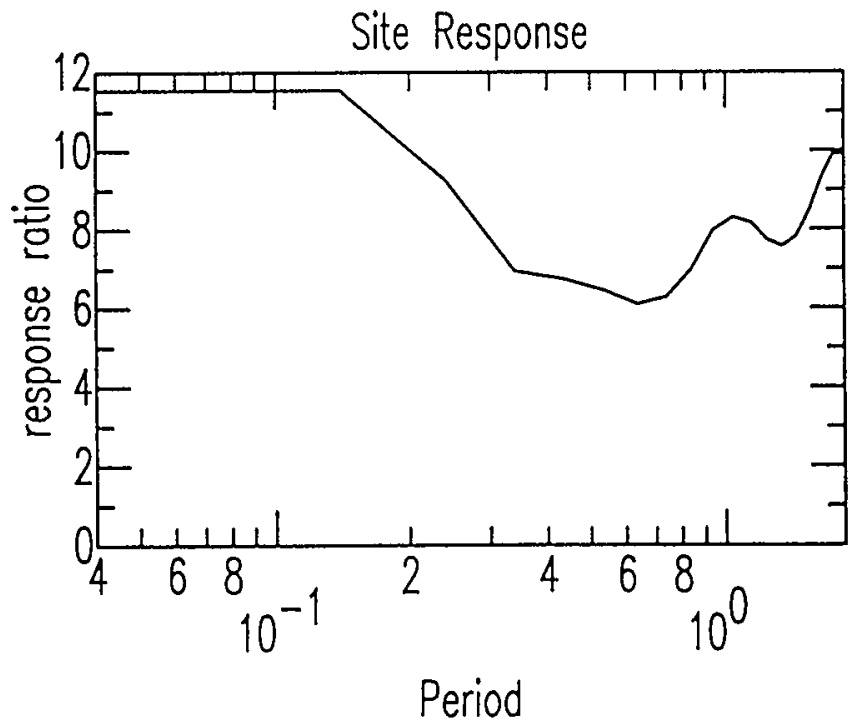


Absolute Acceleration Response

Event 05182046
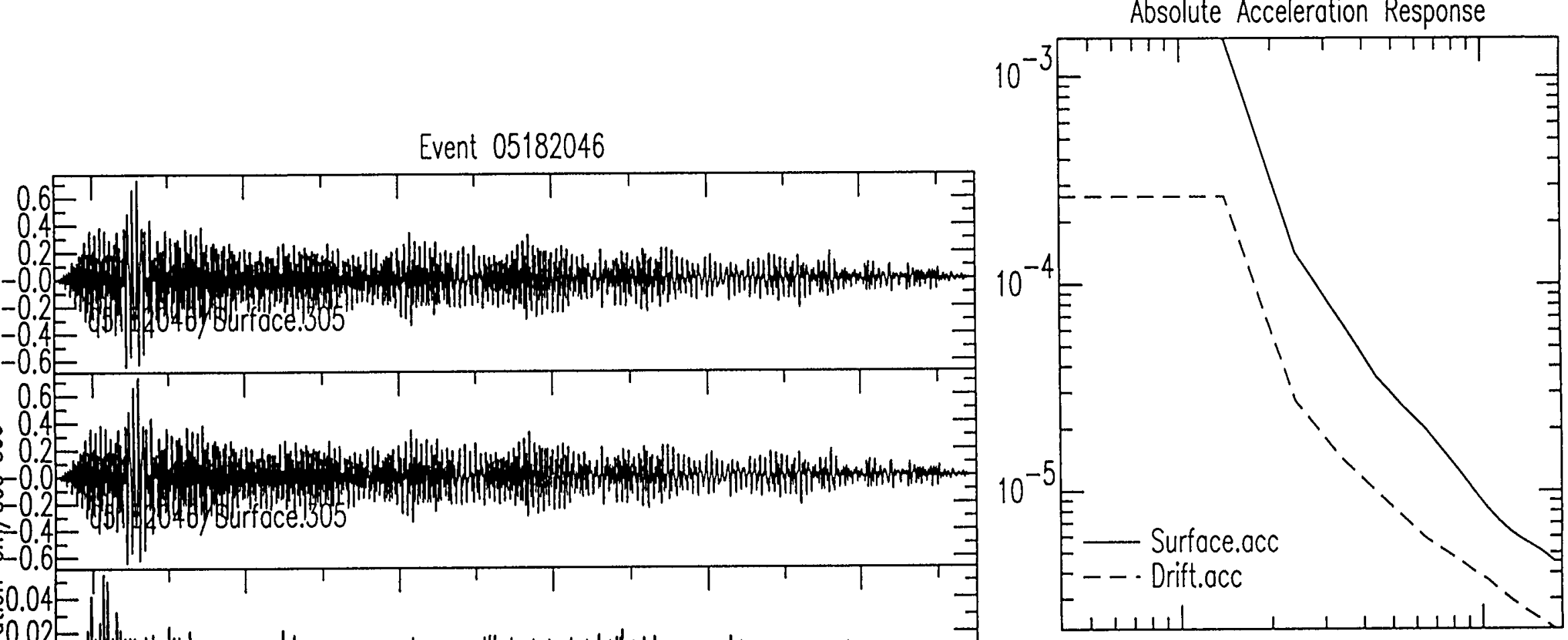
列 ह $0.4=$

\section{.응.04E}

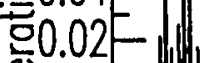

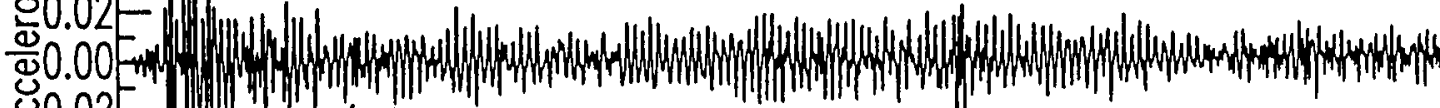
80.02 $-0.04=$

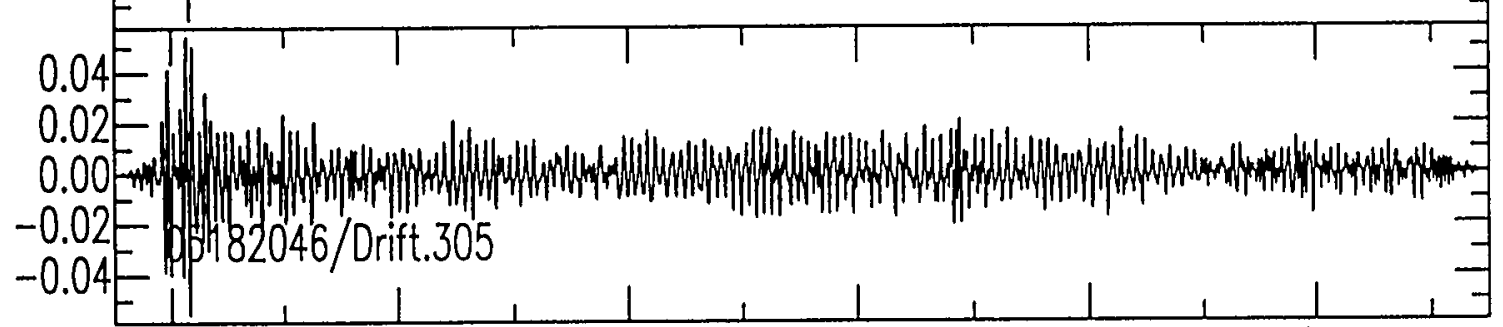

$\frac{6}{a}$

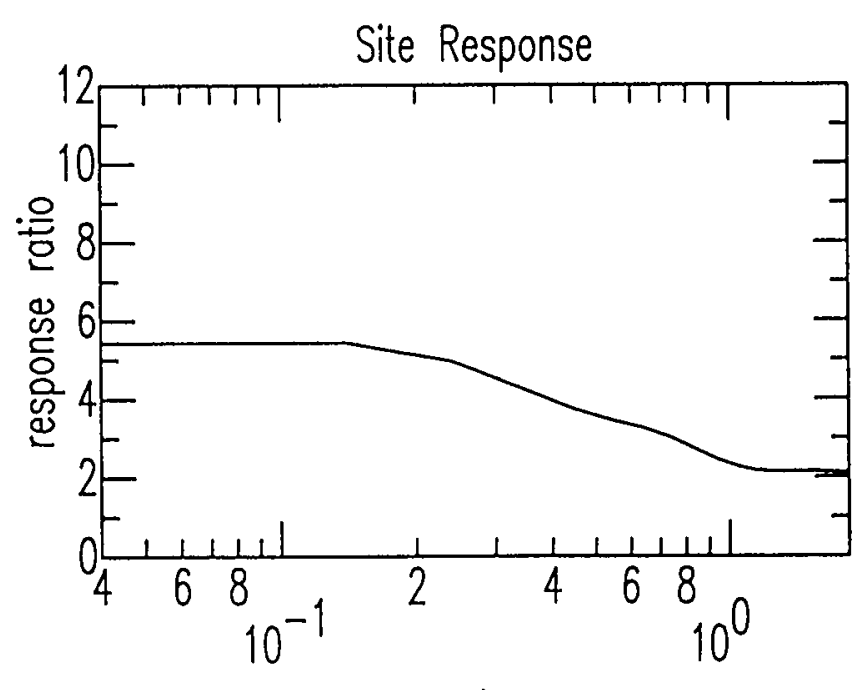

Period 

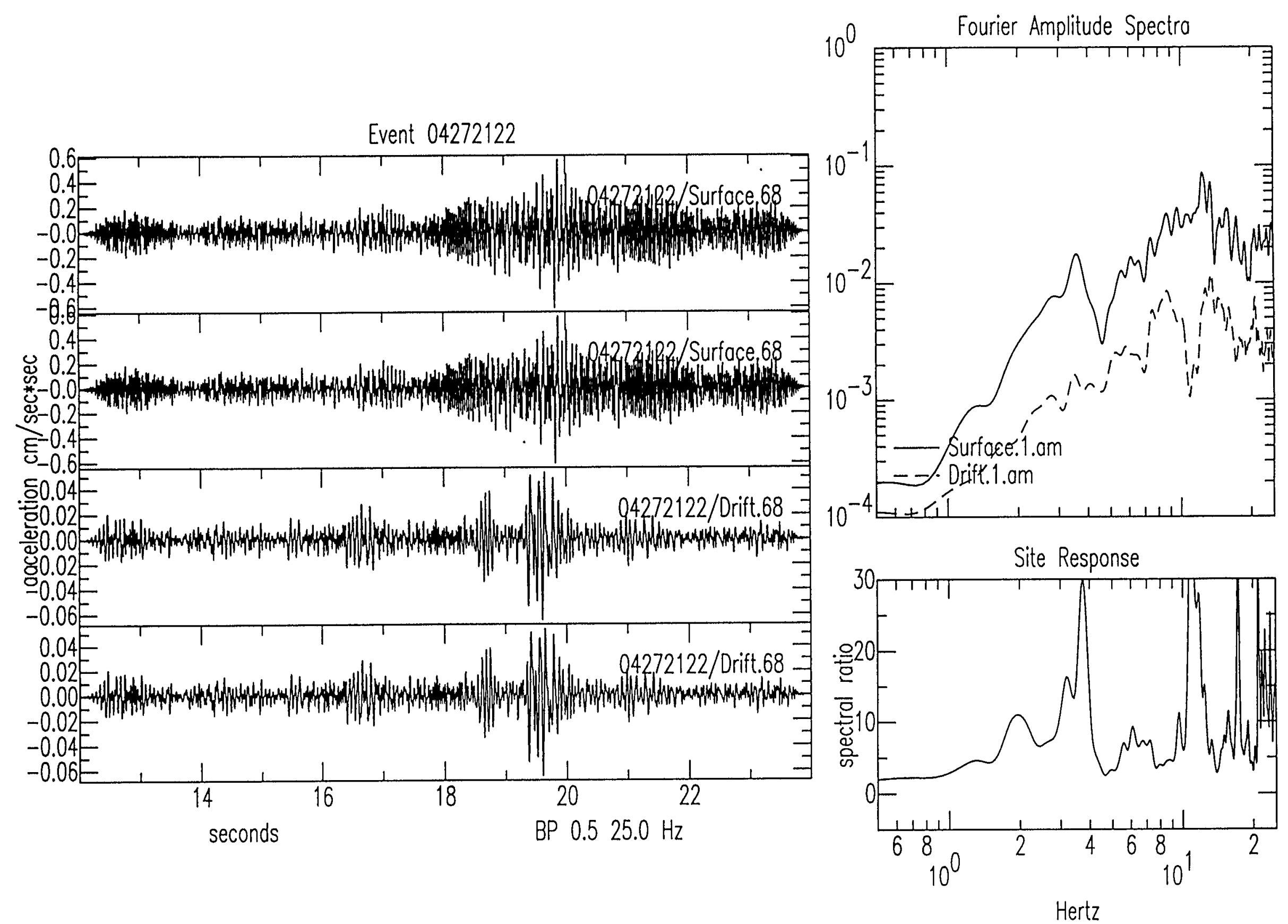

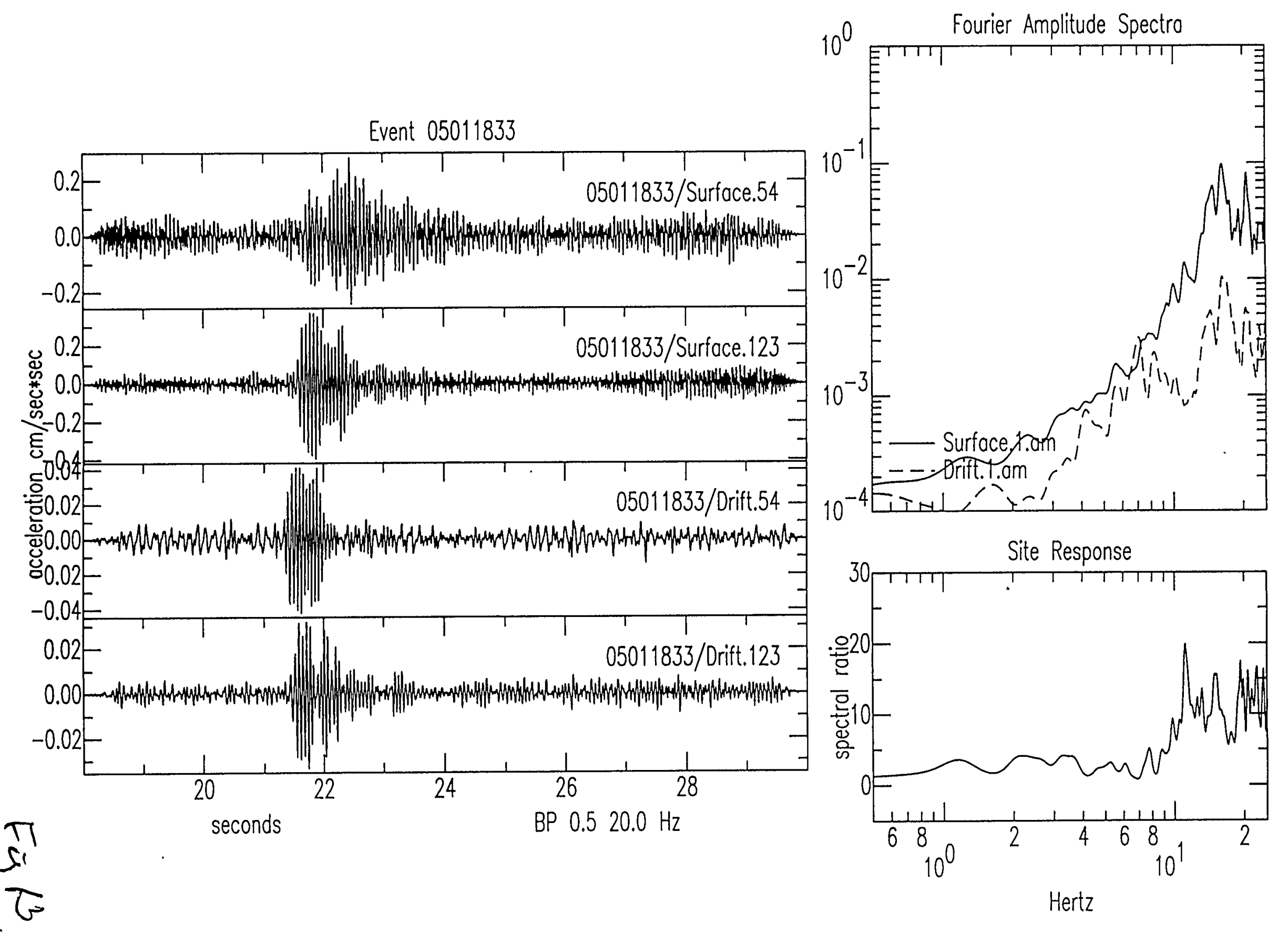

Hertz 

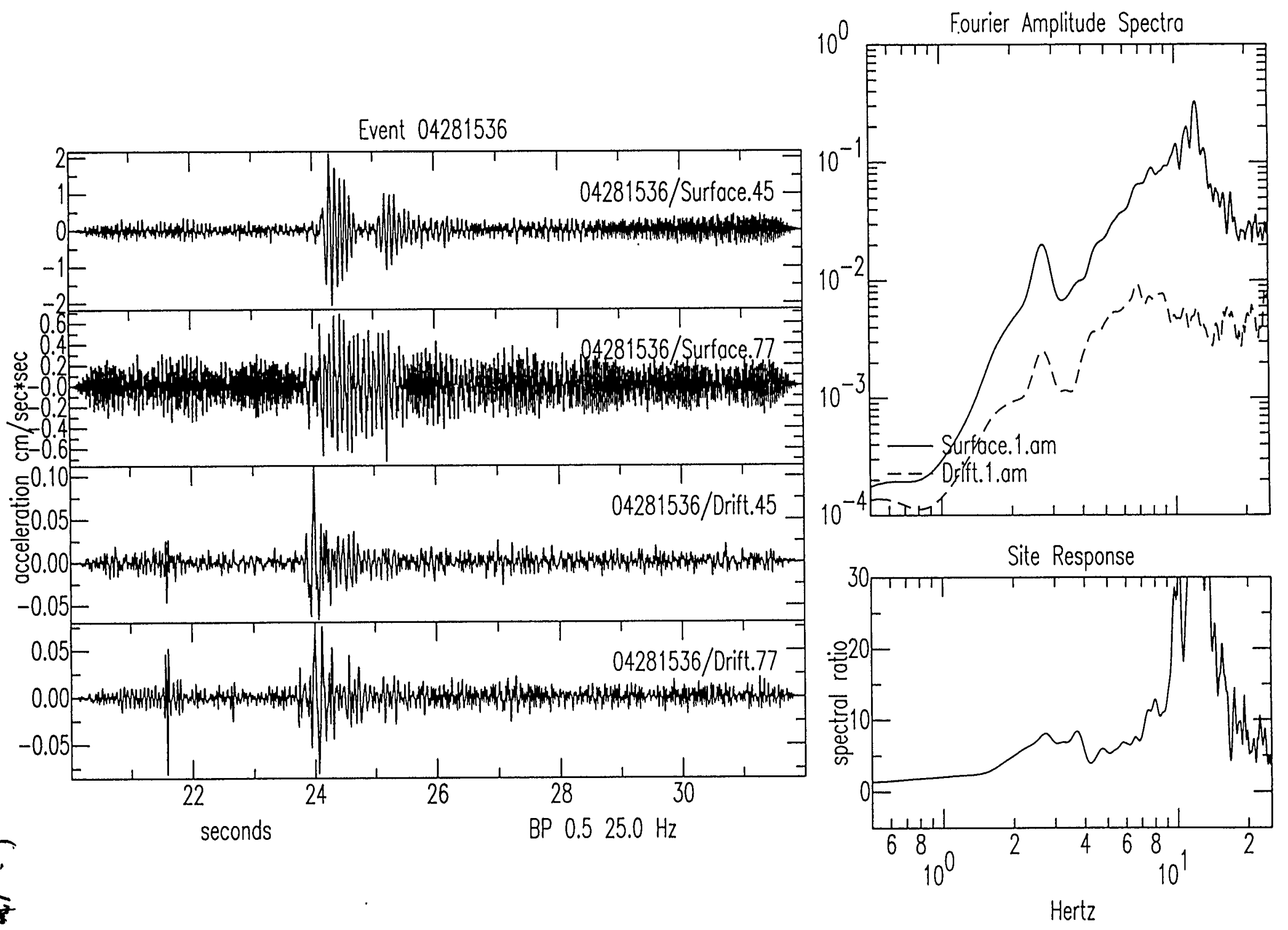

Hertz 

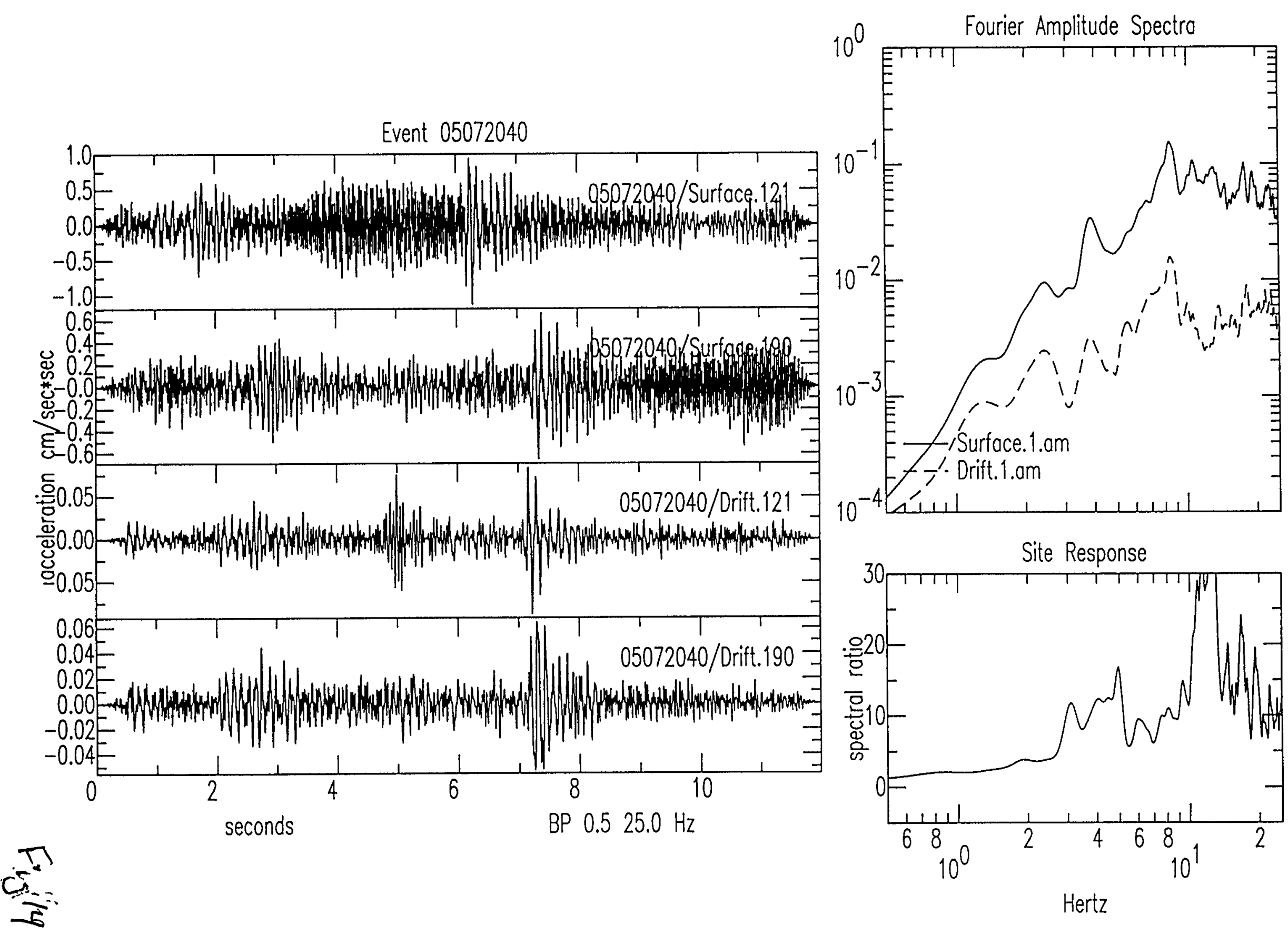

Hertz 

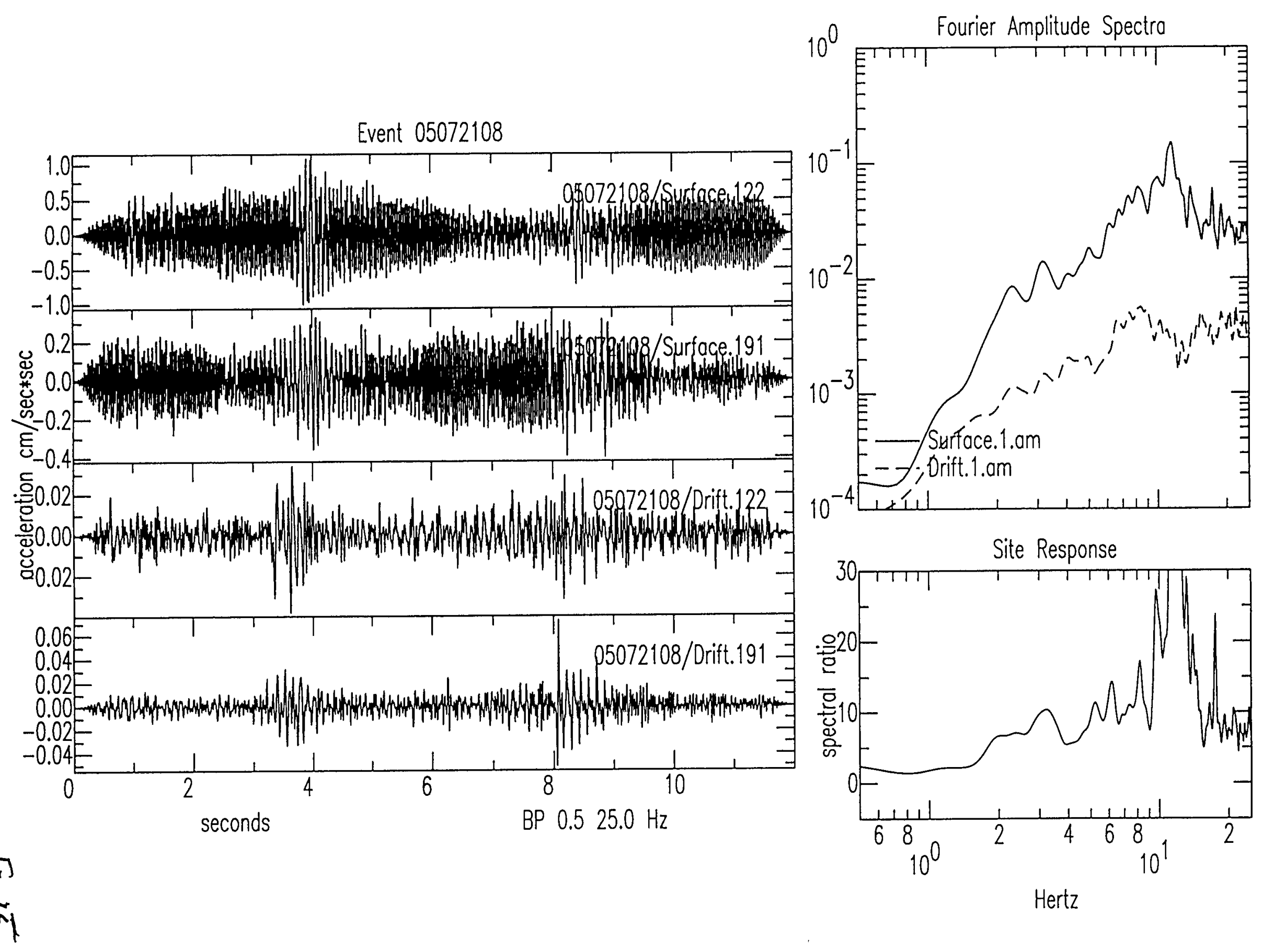

Hertz 

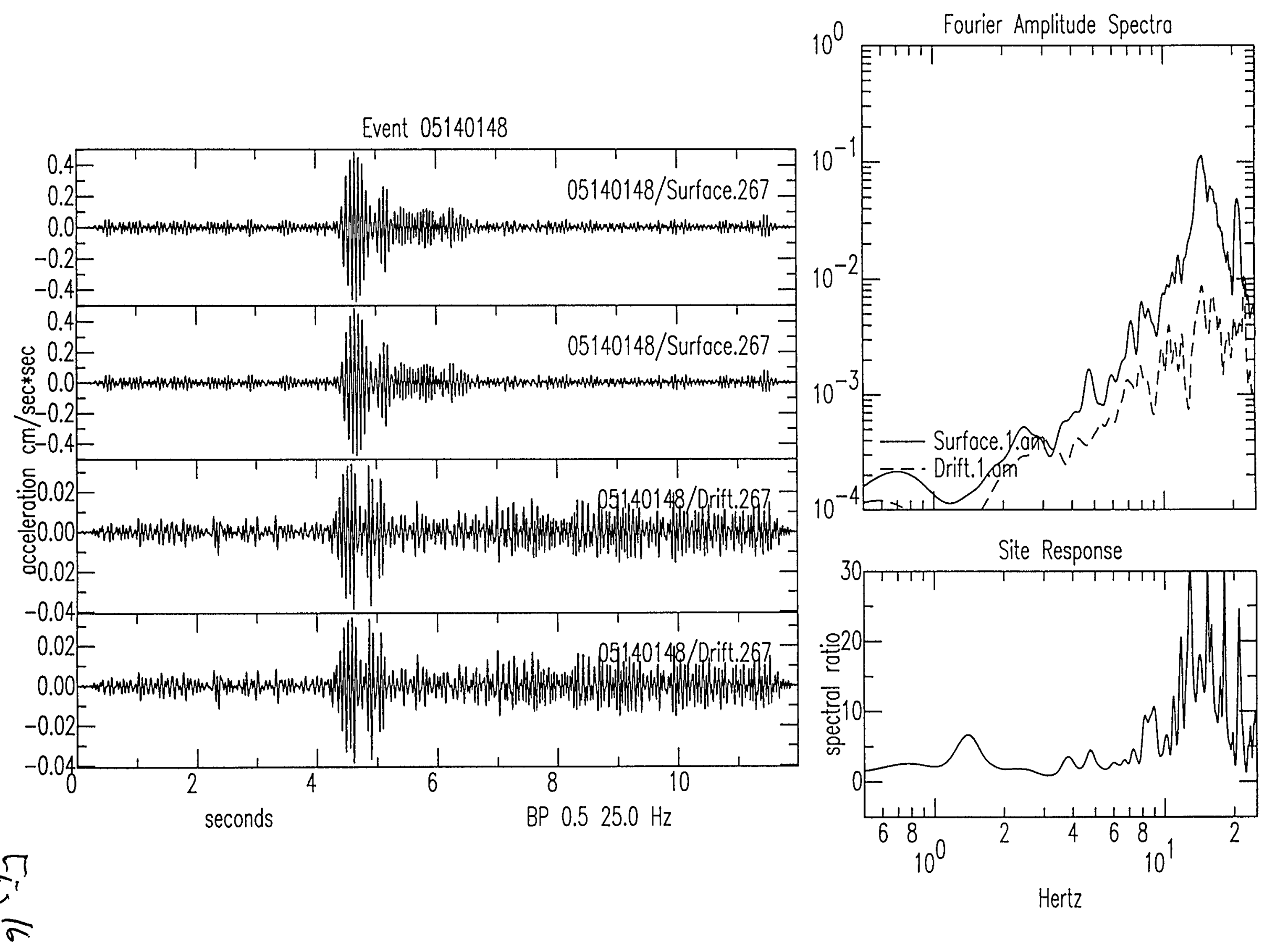

Hertz 
Event 05182043
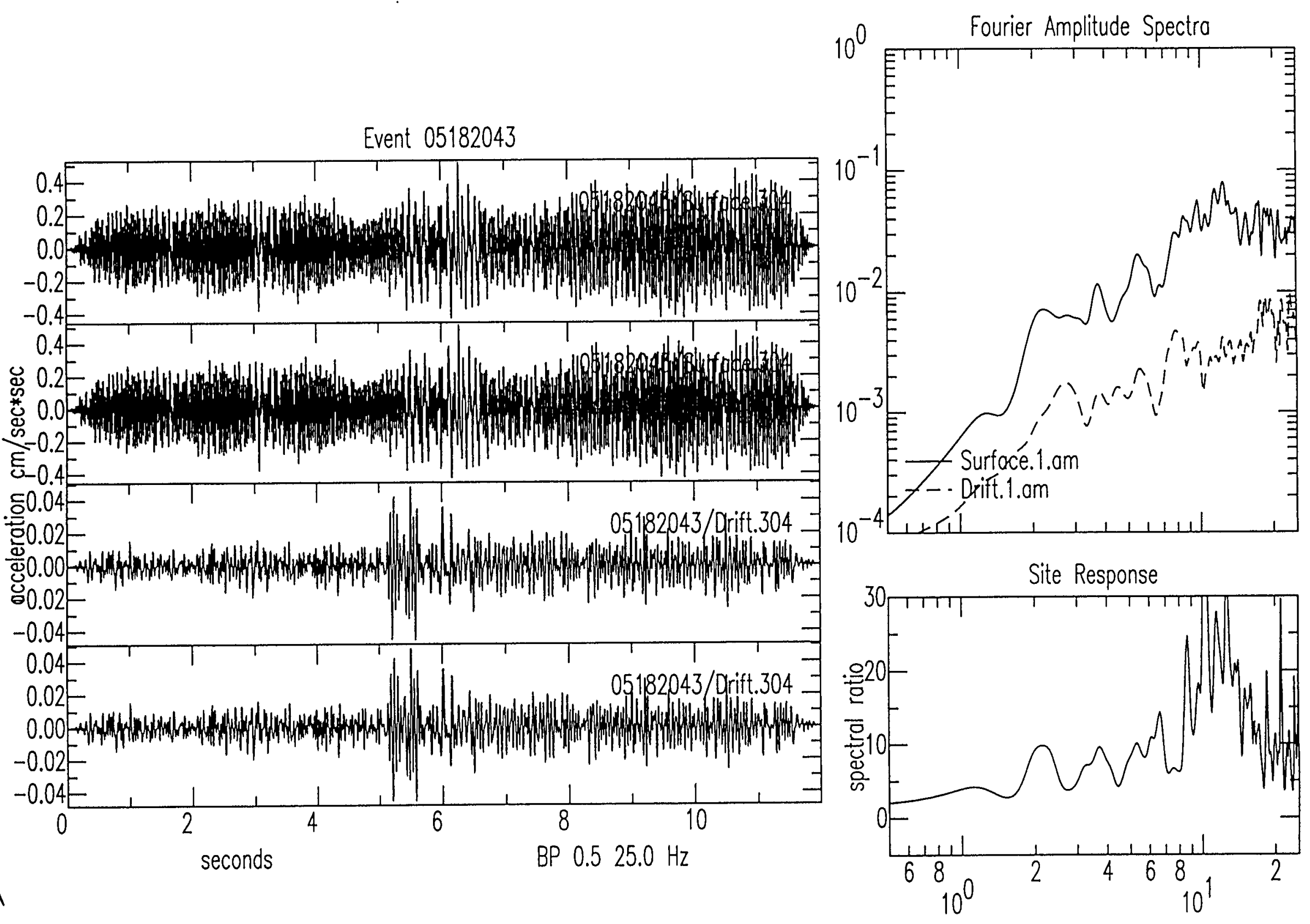

Hertz 

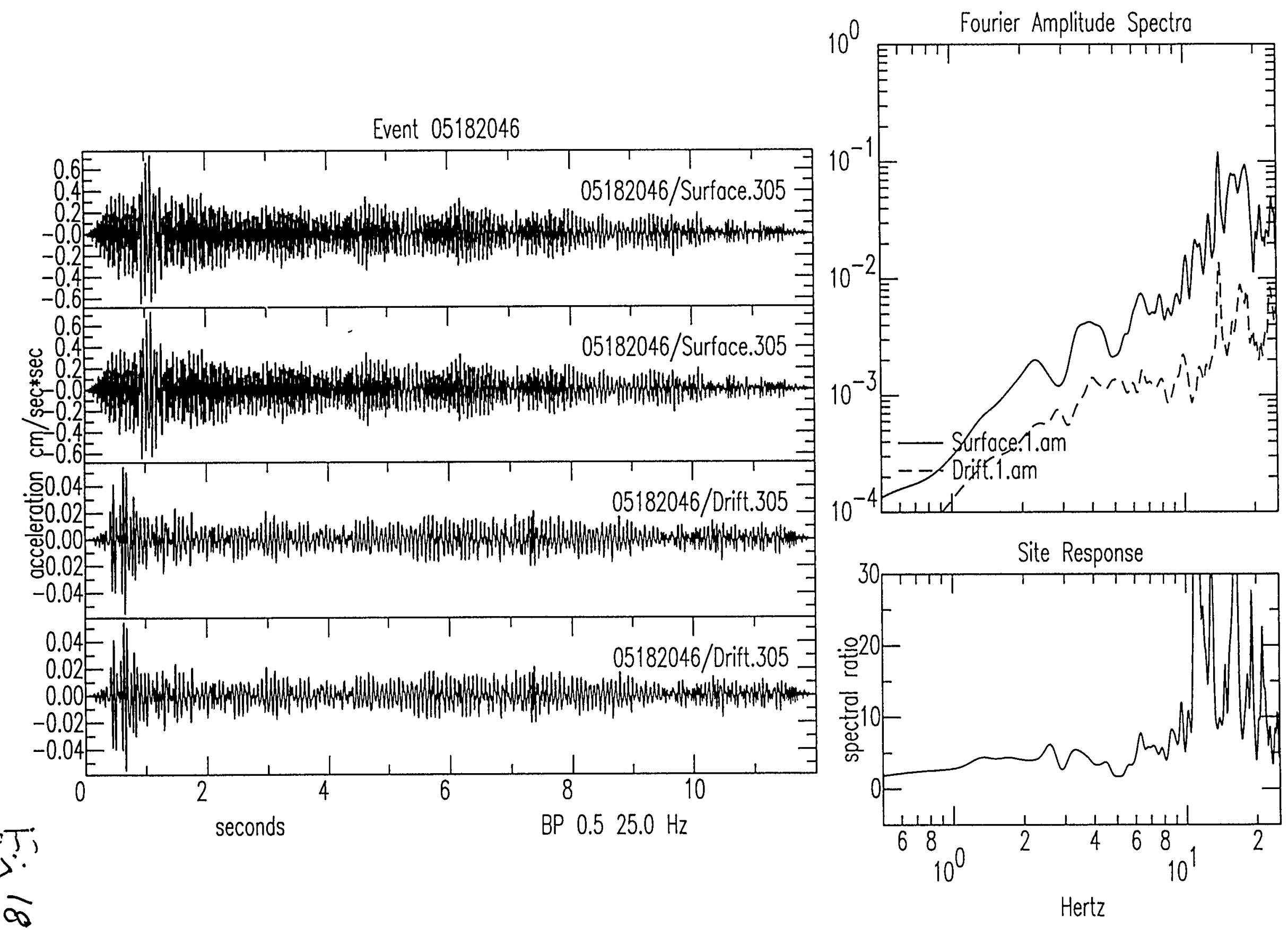

Hertz 

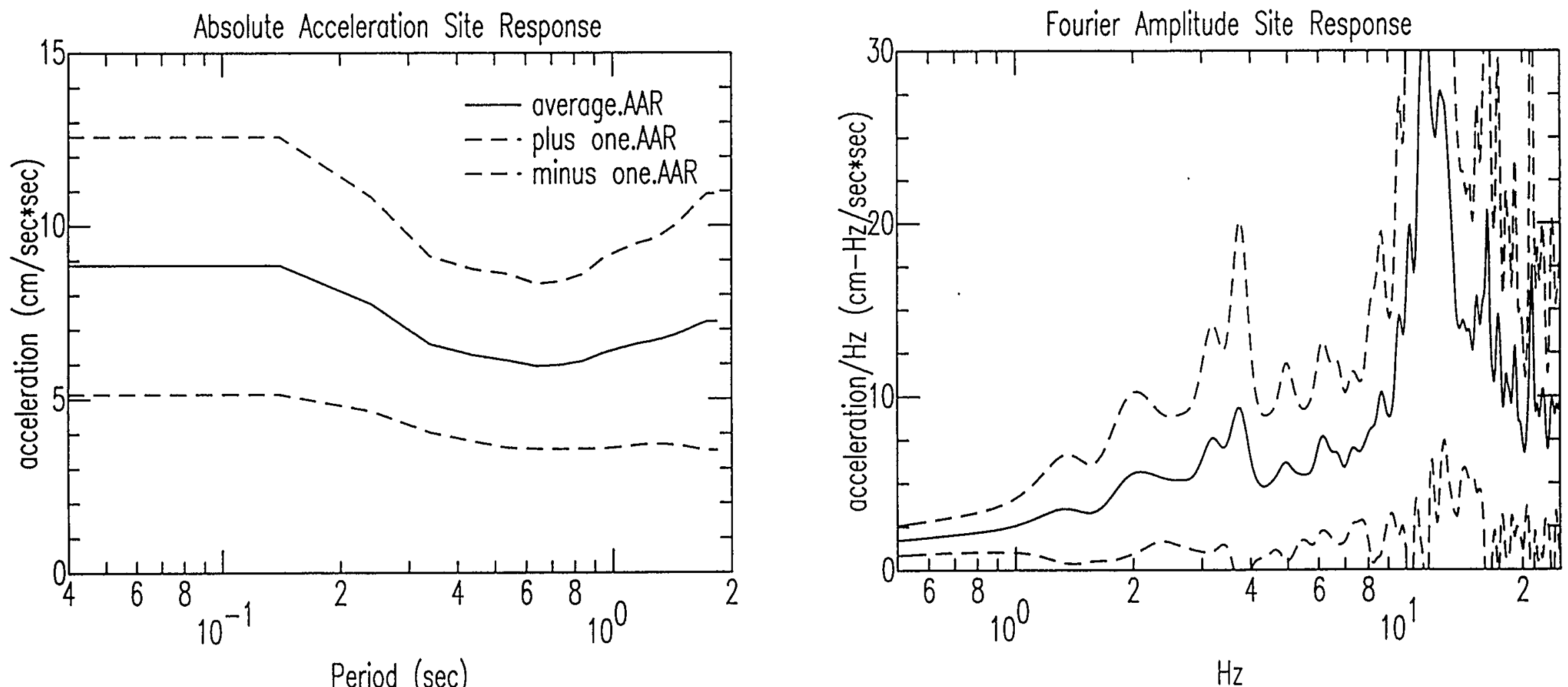

$\int_{3}^{\pi}$ 